\title{
Psychotropic medication non-adherence and its associated factors among patients with major psychiatric disorders: a systematic review and meta-analysis
}

Agumasie Semahegn ${ }^{1,2^{*}}$ D, Kwasi Torpey ${ }^{1}$, Adom Manu', Nega Assefa ${ }^{2}$, Gezahegn Tesfaye ${ }^{2}$ and Augustine Ankomah ${ }^{3}$

\begin{abstract}
Background: Major psychiatric disorders are growing public health concern that attributed $14 \%$ of the global burden of diseases. The management of major psychiatric disorders is challenging mainly due to medication nonadherence. However, there is a paucity of summarized evidence on the prevalence of psychotropic medication non-adherence and associated factors. Therefore, we aimed to summarize existing primary studies' finding to determine the pooled prevalence and factors associated with psychotropic medication non-adherence.

Methods: A total of 4504 studies written in English until December 31, 2017, were searched from the main databases ( $n=3125$ ) (PubMed (MEDLINE), Embase, CINAHL, PsycINFO, and Web of Science) and other relevant sources (mainly from Google Scholar, $n=1379$ ). Study selection, screening, and data extraction were carried out independently by two authors. Observational studies that had been conducted among adult patients (18 years and older) with major psychiatric disorders were eligible for the selection process. Critical appraisal of the included studies was carried out using the Newcastle Ottawa Scale. Systematic synthesis of the studies was carried out to summarize factors associated with psychotropic medication non-adherence. Meta-analysis was carried using Stata 14. Random effects model was used to compute the pooled prevalence, and sub-group analysis at 95\% confidence interval.

Results: Forty-six studies were included in the systematic review. Of these, 35 studies (schizophrenia $(n=9)$, depressive $(n=16)$, and bipolar $(n=10)$ disorders) were included in the meta-analysis. Overall, $49 \%$ of major psychiatric disorder patients were non-adherent to their psychotropic medication. Of these, psychotropic medication non-adherence for schizophrenia, major depressive disorders, and bipolar disorders were 56\%, 50\%, and $44 \%$, respectively. Individual patient's behaviors, lack of social support, clinical or treatment and illness-related, and health system factors influenced psychotropic medication non-adherence.

Conclusion: Psychotropic medication non-adherence was high. It was influenced by various factors operating at different levels. Therefore, comprehensive intervention strategies should be designed to address factors associated with psychotropic medication non-adherence.
\end{abstract}

Systematic review registration: PROSPERO CRD42017067436

Keywords: Medication non-adherence, Psychiatric disorders, Systematic review, Meta-analysis

\footnotetext{
* Correspondence: agucell@yahoo.com

'Department of Population, Family and Reproductive Health, School of

Public Health, College of Health Sciences, University of Ghana, Accra, Ghana

${ }^{2}$ College of Health and Medical Sciences, Haramaya University, Po Box 235,

Harar, Ethiopia

Full list of author information is available at the end of the article
}

(c) The Author(s). 2020 Open Access This article is distributed under the terms of the Creative Commons Attribution 4.0 International License (http://creativecommons.org/licenses/by/4.0/), which permits unrestricted use, distribution, and reproduction in any medium, provided you give appropriate credit to the original author(s) and the source, provide a link to the Creative Commons license, and indicate if changes were made. The Creative Commons Public Domain Dedication waiver (http://creativecommons.org/publicdomain/zero/1.0/) applies to the data made available in this article, unless otherwise stated. 


\section{Background}

Psychiatric disorders have been a global public health challenge. Almost 450 million people are affected by psychiatric disorders worldwide. It contributes $14 \%$ of the overall global burden of diseases, and 30\% of the non-fatal diseases burden, which is worsened by medication non-adherence [1-3]. Psychiatric disorders cost approximately US $\$ 2.5$ trillion in 2010 and are expected to rise up to US\$6.0 trillion by 2030. Lost resources and production, unemployment, absences from work, and premature mortality are some of the indirect economic costs [3]. The World Health Organization (WHO) has designed a comprehensive strategic action plan (20132020) to promote mental well-being, prevent psychiatric disorders, and provide care and support to reduce morbidity, disability, and mortality [4].

Nearly one third (31.7\%) of people who suffer major psychiatric disorders end up with a long-term disability and dependency [5]. Psychiatric disorders are associated with individual factors as well as community social support, cultural, social protection, living standards, and other environmental factors [4]. Compliance to medication is essential but challenging in the management of major psychiatric disorders [6-8]. The WHO defines medication non-adherence as, "a case in which a person's behavior in taking medication does not correspond with agreed recommendations from health personnel" [9]. Patients with major psychiatric disorders are most likely to be non-adherent to medication due to poor reasoning and lack of insight about their illness and treatment $[8,10,11]$.

Psychotropic medication non-adherence can lead to exacerbation of their illness, reduce treatment effectiveness, or leave them less responsive to subsequent treatment. Other consequences of non-adherence include rehospitalization, poor quality of life or psycho-social outcomes, relapse of symptoms, increased co-morbid medical conditions, wastage of health care resources, and increased suicide [7, 8, 12-15]. Research evidence on the level of psychotropic medication non-adherence and its associated factors among patients with major psychiatric disorders is essential to design appropriate interventions to achieve desired treatment goals for both patients and health care providers. Although several primary studies have been conducted on this issue, there has not been any systematic review and meta-analysis carried out to inform policy. Thus, a systematic review and metaanalysis on the level and factors associated with psychotropic medication non-adherence is useful to inform policy makers and program planners. Therefore, the main aim of this systematic review and meta-analysis was to summarize available findings of primary studies to determine the level of psychotropic medication nonadherence and associated factors.

\section{Methods}

\section{Protocol development and registration}

This systematic review and meta-analysis has been registered in the international Prospective Register of Systematic Reviews (PROSPERO 2017:ID:CRD42017067436) [16] and written in accordance with the Preferred Reporting Items for Systematic Review and Meta-analysis (PRISMA) statements guidelines [17] (see Additional file 1). The detail of this systematic review and meta-analysis protocol has been published elsewhere [18].

\section{Search methods for identification of studies}

The Medical Subject Headings (MeSH) and keywords were constructed based on the review question. Studies were searched using search engines, from the main electronic databases (PubMed (Medline), EMBASE, CINAHL, Web of Science, and PsycINFO), and other sources (Google Scholar, reports, thesis, or dissertation). Search strings were constructed using a combination of $\mathrm{MeSH}$ terms such as psychotropic non-adherence, non-compliance, compliance, adherence, determinants, barriers, associated factors, risks, correlates, influencing factors, and major psychiatric disorders (see Additional file 2). The search strings were modified to suit to the corresponding database interface. All of the identified studies were exported to the EndNote citation manager [19], and duplicates were removed.

\section{Eligibility criteria}

Studies were included in the systematic review and or meta-analysis if they fulfill the following eligibility criteria. The criteria were as follows:

- Studies had been conducted among adult patients (18 years and older);

- Studies had been conducted on one or more of the major psychiatric disorders (major depressive disorders, schizophrenia, or bipolar disorder) were eligible;

- Studies reported psychotropic medication nonadherence or adherence and or factors associated with medication non-adherence;

- Studies conducted at community and/or facilitybased;

- Studies used observational study designs (crosssectional, case-control cohort, and or survey);

- Studies were written in English before December 31, 2017;

- Documents (both published and unpublished studies, survey reports, thesis, or dissertations) which were accessible with full text.

\section{Selection of studies into systematic review}

Studies were systematically selected using predetermined eligibility criteria. Studies' title and abstract that 
clearly mentioned either patients with major psychiatric disorder psychotropic medication non-adherence or adherence were selected for the subsequent evaluation. Then, to minimize bias during screening, two authors (AS and GT) independently screened the title and abstract of the studies to proceed to the next step of the studies selection. Studies overview such as aim of the study, design of the study, participants, and main outcome of the study were screened. In this stage, the studies potentially eligible for the full text were selected based on the title and abstract. The full text of the studies selected based on the title and abstract were reassessed independently by two of the authors (AS and GT) for details. The body of the studies' (aims, mainly design, participants, sampling method, findings, conclusions, and recommendations) were assessed. Finally, studies have reported the medication adherence or non-adherence among major psychiatric disorders patients (schizophrenia, major depressive, or bipolar disorders) and associated factors and fulfill the eligibility criteria were selected for the systematic review and meta-analysis. All studies that consider psychiatric disorders as a factor for medication non-adherence were excluded, because studies that consider psychiatric disorders as predictor for the non-adherence to treatment for other illness may not fully assess the adherence level of psychotropic medications. Overall, the studies' selection process was adhered to the PRISMA flow diagram [17] (Fig. 1). Any difference during studies selection process was resolved through consensus.

\section{Measurement of outcome and exposure}

According to the WHO, medication non-adherence is defined as "a case in which a person's behavior in taking medication does not correspond with agreed recommendations from a health personnel". It can be either intentional or unintentional, including failing to initially fill or refill a prescription, discontinuing a medication before completing the course of therapy, taking more or less of a medication than prescribed, and taking a dose at the wrong time [9]. Thus, the main outcome of interest for this systematic review was the level of psychotropic medication non-adherence. Medication nonadherence was measured either as direct report from studies or indirectly by subtracting adherence report from total observations (sample size). Studies' reported non-adherence in another way such as medication noncompliance, non-persistence, dropout, discontinuation, missing, and other alternatives was considered. Moreover, exposure or explanatory variables for the medication non-adherence were measured using synonymous terms such as determinants, predictors, barriers, associated factors, risk factors, and influencing factors.

\section{Quality assurance of the systematic review}

We searched both published and non-peer reviewed studies comprehensively for the systematic review and meta-analysis to minimize publication bias. The electronic or computerized, manual, and email searching methods were applied to have comprehensive search. Eligibility criteria, selection method, quality assessment, data extraction template, and regular meeting for discussion schedule were pre-designed by authors to assure the quality. The studies' methodological quality critical appraisal was carried out using the Newcastle-Ottawa Scale [20] (see Additional file 3).

\section{Data abstraction, synthesis, and statistical analysis}

The two authors (AS and GT) abstracted the data from the included studies and recorded in the data extraction template. Studies' detail descriptions such as an author, study area or country, aim, design, sample size, sampling procedure, and response rate were presented on the table using Microsoft Word (2013) (Table 1). Meanwhile, the raw data of medication non-adherence and total sample size were extracted and stored using Microsoft Excel (2013) template (see Additional file 4). All the meta-analysis were carried out using Stata SE-64 version 14.2 (Stata Corporation, College Station, TX) [66] and based on the recommendation for the meta-analysis of observational studies [67]. Heterogeneity between studies was assessed and substantial heterogeneity was anticipated when $I^{2}$ greater than 75\% [68, 69]. The pooled prevalence (proportion) was estimated using the inverse variance method [66]. The 95\% confidence interval for pooled and sub-group proportion of patients' medication non-adherence was computed. Moreover, the sub-group-pooled proportion of patients' medication non-adherence was performed for schizophrenia, major depressive disorder, and bipolar disorders separately. Random effects model [70] was used for the overall pooled estimate and sub-group meta-analysis.

\section{Publication bias}

Potential publication bias was assessed by inspecting the funnel plot [71]. The funnel plots were constructed using the plot-observed studies only and plot standard error with logit event rate (see Additional file 5). In addition, statistical tests Egger's regression test (one-tailed test), $p=$ 0.683, and Begg's rank correlation (one-tailed), $p=0.831$, were computed to make sure that there is no evidence of publication bias on studies included in this systematic review and meta-analysis. In addition, the tests confirmed that there are no small-study effects in the meta-analysis.

\section{Results}

A total of 46 studies were included in this systematic review and meta-analysis. Each study's key findings and conclusion has summarized in detail (Table 2). 


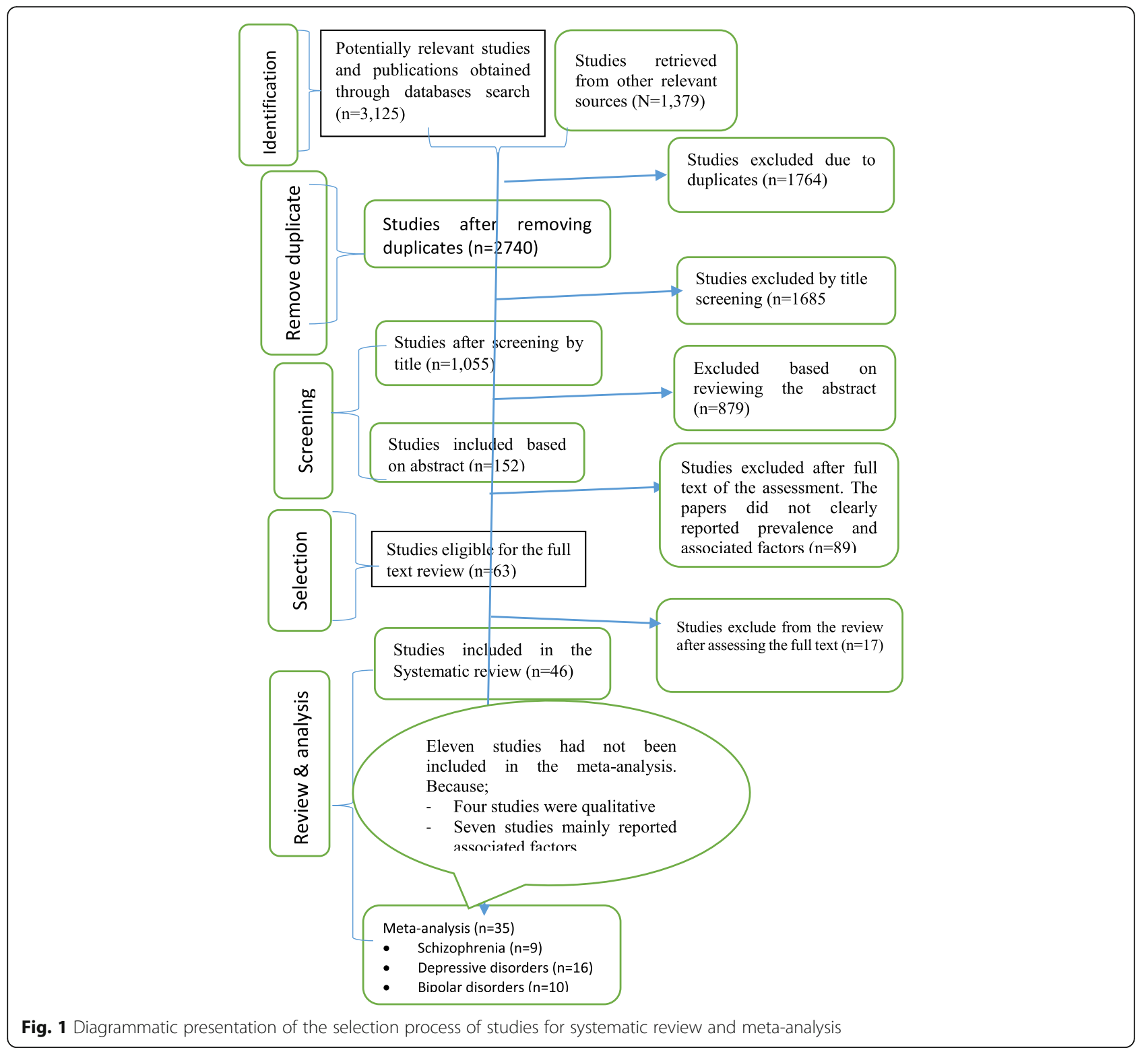

Magnitude of psychotropic medication non-adherence Thirty-five studies were used for meta-analysis to compute the pooled proportion of the psychotropic medication nonadherence. In 35 studies with 63,957 cases from a sample of 120,134 , the pooled prevalence of medication nonadherence among major psychiatric disorders was $49 \%$ (95\% CI 44\%, 55\%). In addition, the psychotropic medication non-adherence was $48 \%, 48 \%, 49 \%$, and $57 \%$ in Africa, North America, Europe, and Asia, respectively (Fig. 2).

Medication non-adherence among schizophrenia patients Sub-group analyses were conducted for studies that reported medication non-adherence among schizophrenia patients. From nine studies with 2643 participants, the medication non-adherence among schizophrenia patients was 56\% (95\% CI 48\%, 63\%). The prevalence in the subgroup analysis was relatively consistent with the overall pooled prevalence (Fig. 3).

\section{Major depressive disorder medication non-adherence}

From 16 studies with 42,255 participants, medication non-adherence among patients with major depressive disorders was 50\% (95\% CI 40\%, 59\%). The prevalence in the sub-group analysis was relatively consistent with the overall pooled prevalence, but a bit lower in Europe (Fig. 4).

\section{Bipolar disorder patients' medication non-adherence}

From 10 studies with 73,250 study participants, medication non-adherence among patients with bipolar disorders was 44\% (95\% CI 43\%, 45\%) (Fig. 5). 
Table 1 Description of studies included for systematic review and meta-analysis $(n=46)$

\begin{tabular}{|c|c|c|c|c|c|c|c|}
\hline Author, country & Study aim & Design & Population & $\begin{array}{l}\text { Sampling } \\
\text { methods }\end{array}$ & $\begin{array}{l}\text { Sample } \\
\text { size }\end{array}$ & Scale used & $\begin{array}{l}\text { Response } \\
\text { rate }(\%)\end{array}$ \\
\hline $\begin{array}{l}\text { Ibrahim et al., } \\
\text { Nigeria [21] }\end{array}$ & $\begin{array}{l}\text { To determine the socio-demographic and } \\
\text { clinical predictors of sub-optimal MA }\end{array}$ & CS & $\begin{array}{l}\text { Schizophrenia } \\
\& \text { depression } \\
\text { patients }\end{array}$ & SRS & 390 & MMAS & 94.8 \\
\hline $\begin{array}{l}\text { Alene et al., } \\
\text { Ethiopia [22] }\end{array}$ & To evaluate MA and associated factors & CS & $\begin{array}{l}\text { Schizophrenia } \\
\text { patients }\end{array}$ & Purposive & 336 & CFR & 87.5 \\
\hline $\begin{array}{l}\text { Eticha et al., } \\
\text { Ethiopia [23] }\end{array}$ & $\begin{array}{l}\text { To investigate factors associated with MA } \\
\text { among patients with schizophrenia }\end{array}$ & CS & $\begin{array}{l}\text { Schizophrenia } \\
\text { patients }\end{array}$ & Consecutive & 393 & MARS & 97.5 \\
\hline $\begin{array}{l}\text { Kenfe et al., } \\
\text { Ethiopia [24] }\end{array}$ & $\begin{array}{l}\text { To assess the magnitude and associated } \\
\text { factors of MNA }\end{array}$ & CS & $\begin{array}{l}\text { Psychiatric } \\
\text { patients }\end{array}$ & Consecutive & 422 & MMAS & 100 \\
\hline $\begin{array}{l}\text { Hibdye et al., } \\
\text { Ethiopia [25] }\end{array}$ & $\begin{array}{l}\text { To assess the prevalence and factors } \\
\text { associated with MNA }\end{array}$ & CS & $\begin{array}{l}\text { Bipolar } \\
\text { disorders } \\
\text { patients }\end{array}$ & Systematic & 410 & MMAS & 97 \\
\hline $\begin{array}{l}\text { Anne et al., USA } \\
\text { [26] }\end{array}$ & To examine the barriers of antidepressant MA & Longitudinal & $\begin{array}{l}\text { Depression } \\
\text { patients }\end{array}$ & Multistage & 134 & $\begin{array}{l}\text { Brief } \\
\text { interview }\end{array}$ & 90 \\
\hline $\begin{array}{l}\text { Hill et al., Ireland } \\
{[27]}\end{array}$ & To examined concurrent predictors of MNA & cohort & $\begin{array}{l}\text { Psychosis } \\
\text { Patients }\end{array}$ & Restrictive & 171 & $\begin{array}{l}\text { Interview } \\
\text { \&DAl }\end{array}$ & NR \\
\hline $\begin{array}{l}\text { Moritz et al., } \\
\text { Germany [28] }\end{array}$ & $\begin{array}{l}\text { To investigate attitudes toward psychotic } \\
\text { symptoms affect MNA }\end{array}$ & Cohort & $\begin{array}{l}\text { Schizophrenia } \\
\text { patients }\end{array}$ & Restrictive & 113 & $\begin{array}{l}\text { Self-report } \\
\text { questions }\end{array}$ & NR \\
\hline $\begin{array}{l}\text { Mert et al., Turkey } \\
\text { [29] }\end{array}$ & To evaluate factors resulting in MNA & CS & $\begin{array}{l}\text { Schizophrenic, } \\
\text { depressive } \\
\text { patients }\end{array}$ & $\begin{array}{l}\text { Patients } \\
\text { receiving } \\
\text { treatment }\end{array}$ & 203 & SCID-I & NR \\
\hline $\begin{array}{l}\text { Novick et al., } \\
\text { Multi-country- } \\
\text { European [30] }\end{array}$ & $\begin{array}{l}\text { To explore the relationship between insight } \\
\text { and MA }\end{array}$ & $\mathrm{CS}$ & $\begin{array}{l}\text { Schizophrenia } \\
\text { and bipolar } \\
\text { patients }\end{array}$ & SRS & 903 & MARS & NR \\
\hline $\begin{array}{l}\text { Hillary, Nigeria } \\
\text { [31] }\end{array}$ & $\begin{array}{l}\text { To evaluate the level of patients' MNA and } \\
\text { associated factors }\end{array}$ & $\mathrm{CS}$ & $\begin{array}{l}\text { Psychiatric } \\
\text { disorders } \\
\text { patients }\end{array}$ & Convenient & 200 & MMAS & NR \\
\hline $\begin{array}{l}\text { Ibrahim et al., } \\
\text { Nigeria [32] }\end{array}$ & $\begin{array}{l}\text { To assessed the prevalence and exclusively } \\
\text { X-rayed medication-related factors of MNA }\end{array}$ & $\mathrm{CS}$ & $\begin{array}{l}\text { Schizophrenia } \\
\text { and bipolar } \\
\text { patients }\end{array}$ & Convenient & 358 & MMAS & 94.2 \\
\hline $\begin{array}{l}\text { Dibonaventura } \\
\text { et al., USA [33] }\end{array}$ & $\begin{array}{l}\text { To examine the relationship between these } \\
\text { variables among community-dwelling patients } \\
\text { with schizophrenia }\end{array}$ & $\mathrm{CS}$ & $\begin{array}{l}\text { Adults } \\
\text { schizophrenia } \\
\text { patients }\end{array}$ & Convenience & 876 & MMAS & NR \\
\hline $\begin{array}{l}\text { Gurmu et al., } \\
\text { Ethiopia [34] }\end{array}$ & $\begin{array}{l}\text { To determine the statistical significance } \\
\text { of the association of variables with adherence }\end{array}$ & $\mathrm{CS}$ & $\begin{array}{l}\text { Patients who } \\
\text { visited } \\
\text { psychiatric } \\
\text { clinic }\end{array}$ & Convenience & 209 & MARS & 96.3 \\
\hline $\begin{array}{l}\text { Magura et al., } \\
\text { USA [35] }\end{array}$ & $\begin{array}{l}\text { To identify predictors of MA among } \\
\text { psychiatric patients }\end{array}$ & CS & $\begin{array}{l}\text { Psychiatric } \\
\text { disorders } \\
\text { patients }\end{array}$ & $\begin{array}{l}\text { Patients } \\
\text { fulfilled } \\
\text { eligibility } \\
\text { criteria }\end{array}$ & 131 & MARS & NR \\
\hline $\begin{array}{l}\text { Kikkert et al., } 4 \\
\text { European } \\
\text { countries [36]. }\end{array}$ & $\begin{array}{l}\text { To explore factors influencing MA of } \\
\text { schizophrenia patients }\end{array}$ & $\begin{array}{l}\text { qualitative } \\
\text { study }\end{array}$ & $\begin{array}{l}\text { Schizophrenia } \\
\text { patients }\end{array}$ & Purposive & 91 & Qualitative & NA \\
\hline $\begin{array}{l}\text { Teferra et al., } \\
\text { Ethiopia [37] }\end{array}$ & $\begin{array}{l}\text { To improve understanding of the underlying } \\
\text { reasons for MA }\end{array}$ & $\begin{array}{l}\text { Qualitative } \\
\text { study }\end{array}$ & $\begin{array}{l}\text { Schizophrenia } \\
\text { patients \& } \\
\text { caregivers }\end{array}$ & Purposive & 43 & FGDs & NR \\
\hline $\begin{array}{l}\text { Sher et al., USA } \\
\text { [38] }\end{array}$ & $\begin{array}{l}\text { To evaluate the effects of caregivers' causal } \\
\text { beliefs about depression and their perceptions } \\
\text { of stigma on MA }\end{array}$ & $\begin{array}{l}\text { longitudinal } \\
\text { study }\end{array}$ & MDD patients & Multistage & 47 & $\begin{array}{l}\text { Link's } \\
\text { scale }\end{array}$ & NR \\
\hline $\begin{array}{l}\text { Mohamed et al., } \\
\text { USA [39] }\end{array}$ & $\begin{array}{l}\text { To examine the strength of association of } \\
\text { measures of both insight and attitudes toward } \\
\text { MA }\end{array}$ & CS & $\begin{array}{l}\text { Chronic } \\
\text { schizophrenia } \\
\text { patients }\end{array}$ & Purposive & 1432 & $\begin{array}{l}\text { DAl, pill } \\
\text { count, } \\
\text { ITAQ }\end{array}$ & NR \\
\hline Sava, Turkey [40] & $\begin{array}{l}\text { To investigate the relationship between } \\
\text { treatment adherence and the level of MA }\end{array}$ & CS & $\begin{array}{l}\text { Comprised of } \\
\text { euthymic } \\
\text { patients }\end{array}$ & $\begin{array}{l}\text { Patients } \\
\text { attending } \\
\text { their follow- } \\
\text { up }\end{array}$ & 147 & $\begin{array}{l}\text { Self-report } \\
\text { question }\end{array}$ & NR \\
\hline
\end{tabular}


Table 1 Description of studies included for systematic review and meta-analysis $(n=46)$ (Continued)

\begin{tabular}{|c|c|c|c|c|c|c|c|}
\hline Author, country & Study aim & Design & Population & $\begin{array}{l}\text { Sampling } \\
\text { methods }\end{array}$ & $\begin{array}{l}\text { Sample } \\
\text { size }\end{array}$ & Scale used & $\begin{array}{l}\text { Response } \\
\text { rate }(\%)\end{array}$ \\
\hline Sirey, USA [41] & $\begin{array}{l}\text { To examine the extent to which perceived } \\
\text { stigma affected treatment discontinuation }\end{array}$ & CS & $\begin{array}{l}\text { Psychiatric } \\
\text { patients }\end{array}$ & Multi-stage & 92 & SCS & NR \\
\hline $\begin{array}{l}\text { Sajatovic, USA } \\
{[42]}\end{array}$ & $\begin{array}{l}\text { To examined MA among patients with bipolar } \\
\text { disorder }\end{array}$ & Longitudinal & Bipolar patients & All & 44,637 & MPR & NR \\
\hline $\begin{array}{l}\text { Sajatovic, USA } \\
\text { [43] }\end{array}$ & $\begin{array}{l}\text { To examine antipsychotic MA among bipolar } \\
\text { disorder }\end{array}$ & Longitudinal & Bipolar patients & All & 73,964 & MPR & NR \\
\hline John, USA [44] & $\begin{array}{l}\text { To investigate the factors associated with } \\
\text { non-adherence }\end{array}$ & CS & $\begin{array}{l}\text { Bipolar disorder } \\
\text { patients }\end{array}$ & $\begin{array}{l}\text { Interactive } \\
\text { panel }\end{array}$ & 469 & $\begin{array}{l}\text { Adapted } \\
\text { tool }\end{array}$ & NR \\
\hline $\begin{array}{l}\text { Iseselo et al., } \\
\text { Tanzania [45] }\end{array}$ & $\begin{array}{l}\text { To determine the psychosocial problems of } \\
\text { mental illness }\end{array}$ & $\begin{array}{l}\text { Qualitative } \\
\text { study }\end{array}$ & $\begin{array}{l}\text { Patients } \\
\text { families/care } \\
\text { givers }\end{array}$ & Purposive & 14 & $\begin{array}{l}\text { Interview } \\
\text { and FGDs }\end{array}$ & NR \\
\hline $\begin{array}{l}\text { Olivares, Spain } \\
{[46]}\end{array}$ & $\begin{array}{l}\text { To evaluate long term treatment outcomes in } \\
\text { routine clinical practice }\end{array}$ & Cohort & $\begin{array}{l}\text { Schizophrenia } \\
\text { patients }\end{array}$ & $\begin{array}{l}\text { Prospective } \\
\text { chart review }\end{array}$ & 1622 & GAF score & NR \\
\hline $\begin{array}{l}\text { Charlotte, } \\
\text { Sweden [47] }\end{array}$ & $\begin{array}{l}\text { To identify predictors of MNA to } \\
\text { antidepressant treatment }\end{array}$ & $\mathrm{CS}$ & MDD patients & SRS & 1031 & $\begin{array}{l}\text { CRF \& } \\
\text { TDM }\end{array}$ & NR \\
\hline $\begin{array}{l}\text { Adeponle et al., } \\
\text { Nigeria [48] }\end{array}$ & $\begin{array}{l}\text { To assess relationship of family engagement } \\
\text { and MA }\end{array}$ & cohort & $\begin{array}{l}\text { Psychiatric } \\
\text { patients }\end{array}$ & Purposive & 81 & $\begin{array}{l}\text { Case Note } \\
\text { review }\end{array}$ & NR \\
\hline $\begin{array}{l}\text { Rashid, Malaysia } \\
\text { [49] }\end{array}$ & $\begin{array}{l}\text { To determine the treatment related risk factors } \\
\text { with the default of depression treatment }\end{array}$ & CC & MDD patients & Convenient & 148 & $\begin{array}{l}\text { Self- } \\
\text { reported } \\
\text { question }\end{array}$ & 86 \\
\hline Roy, India [50] & $\begin{array}{l}\text { To examine factors associated with poor drug } \\
\text { compliance. }\end{array}$ & CS & $\begin{array}{l}\text { Psychiatric } \\
\text { patients }\end{array}$ & Consecutive & 100 & Checklist & NR \\
\hline Omran, Iran [51] & $\begin{array}{l}\text { To describe psychiatrists' attributions on } \\
\text { non-compliance }\end{array}$ & $\mathrm{CS}$ & $\begin{array}{l}\text { Psychiatric } \\
\text { patients }\end{array}$ & SRS & 500 & $\begin{array}{l}\text { Interview } \\
\text { using } \\
\text { checklist }\end{array}$ & NR \\
\hline $\begin{array}{l}\text { Tara et al., } \\
\text { Canada [52] }\end{array}$ & To assess levels of MNA and determinants & CS & $\begin{array}{l}\text { Psychiatric } \\
\text { patients }\end{array}$ & SRS & 80 & Self-report & NR \\
\hline $\begin{array}{l}\text { Banerjee, India } \\
{[53]}\end{array}$ & $\begin{array}{l}\text { To assess the correlates of MNA to unipolar } \\
\text { patients }\end{array}$ & CS & $\begin{array}{l}\text { Psychiatric with } \\
\text { depression }\end{array}$ & Purposive & 239 & MMAS & 97.2 \\
\hline Oliver, Spain [54] & $\begin{array}{l}\text { To describe MA among patients with } \\
\text { depression }\end{array}$ & CS & $\begin{array}{l}\text { Psychiatric } \\
\text { patients with } \\
\text { Depression }\end{array}$ & SRS & 212 & $\begin{array}{l}\text { Medical } \\
\text { record }\end{array}$ & NR \\
\hline Dave, UK [55] & $\begin{array}{l}\text { To assess the patterns, incidence and } \\
\text { predictors of therapy discontinuation }\end{array}$ & Cohort & $\begin{array}{l}\text { MDD patients } \\
\text { (2006-2008) }\end{array}$ & SRS & 13,927 & $\mathrm{PHQ}$ & 91.2 \\
\hline $\begin{array}{l}\text { Mahaye, South } \\
\text { Africa [56] }\end{array}$ & $\begin{array}{l}\text { To assess the levels of MA and its associated } \\
\text { factors }\end{array}$ & CS & $\begin{array}{l}\text { Psychiatric } \\
\text { patients }\end{array}$ & Convenient & 95 & MMAS & NR \\
\hline $\begin{array}{l}\text { Sundell, Sweden } \\
\text { [57] }\end{array}$ & $\begin{array}{l}\text { To analyze whether socio-economic factors } \\
\text { influence early discontinuation }\end{array}$ & CS & $\begin{array}{l}\text { Depression } \\
\text { patients }\end{array}$ & SRS & 6536 & MARS & NR \\
\hline Akincigil, [58] & $\begin{array}{l}\text { To describe patient and provider level factors } \\
\text { associated with treatment adherence. }\end{array}$ & Cohort & $\begin{array}{l}\text { Psychiatric } \\
\text { patients }\end{array}$ & Convenient & 4312 & $\begin{array}{l}\text { pharmacy } \\
\text { claims }\end{array}$ & NR \\
\hline $\begin{array}{l}\text { Fawad, Pakistan } \\
\text { [11] }\end{array}$ & To elucidate predictors of non-adherence & CS & $\begin{array}{l}\text { Psychiatric } \\
\text { patients }\end{array}$ & Convenient & 128 & $\begin{array}{l}\text { Adapted } \\
\text { question }\end{array}$ & 94.8 \\
\hline $\begin{array}{l}\text { Prukkanone et al., } \\
\text { Thailand [59] }\end{array}$ & $\begin{array}{l}\text { To quantify the adherence rate to and } \\
\text { associated factors }\end{array}$ & Cohort & $\begin{array}{l}\text { Depression } \\
\text { patients }\end{array}$ & Convenient & 1058 & MPR & NR \\
\hline $\begin{array}{l}\text { Shigemur, Japan } \\
{[60]}\end{array}$ & $\begin{array}{l}\text { To identify predictors of antidepressant } \\
\text { adherence }\end{array}$ & CS & MDD patients & Online survey & 1151 & Checklist & NR \\
\hline $\begin{array}{l}\text { Bambouer et al., } \\
\text { USA [61]. }\end{array}$ & $\begin{array}{l}\text { To examined compliance and faxed alerts to } \\
\text { physicians in } 2003\end{array}$ & Cohort & $\begin{array}{l}\text { Psychiatric } \\
\text { patients }\end{array}$ & Purposive & 13,128 & MMAS & NR \\
\hline $\begin{array}{l}\text { Demyttenaere } \\
\text { et al., Belgium } \\
\text { [62] }\end{array}$ & $\begin{array}{l}\text { To investigate of compliance in patients with } \\
\text { MDD }\end{array}$ & CS & Mdd & SRS & 85 & MEMS & NR \\
\hline Mascha, [63] & $\begin{array}{l}\text { To evaluate adherence to antidepressant } \\
\text { among depressed patients }\end{array}$ & Cohort & $\begin{array}{l}\text { Depression } \\
\text { Patients }\end{array}$ & Purposive & 131 & MMAS & NR \\
\hline Baldessarini et al., & To sought risk factors to guide clinical & CS & Bipolar patients & SRS & 429 & Self-report & NR \\
\hline
\end{tabular}


Table 1 Description of studies included for systematic review and meta-analysis $(n=46)$ (Continued)

\begin{tabular}{|c|c|c|c|c|c|c|c|}
\hline Author, country & Study aim & Design & Population & $\begin{array}{l}\text { Sampling } \\
\text { methods }\end{array}$ & $\begin{array}{l}\text { Sample } \\
\text { size }\end{array}$ & Scale used & $\begin{array}{l}\text { Response } \\
\text { rate (\%) }\end{array}$ \\
\hline USA [64] & prediction of non-adherence & & & & & PRFs & \\
\hline $\begin{array}{l}\text { Nega et al., } \\
\text { Ethiopia [65] }\end{array}$ & $\begin{array}{l}\text { To assess psychotropic MNA and associated } \\
\text { factors }\end{array}$ & CS & $\begin{array}{l}\text { Psychiatric } \\
\text { disorder } \\
\text { patients }\end{array}$ & SRS & 613 & MMAS & 92.9 \\
\hline
\end{tabular}

CC case control, CS cross-sectional, CRFs case report forms, FGD focus group discussion, GAF Global Assessment of Functioning score, ITAQ Insight and Treatment Attitudes Questionnaire, MA medication adherence, MNA medication non-adherence, MMAS Morisky Medication Adherence Scale, CFR compliant fill rate, MARS Medication Adherence Rating Scale, MEMS Medication Monitoring System, MPR Medication Possession Ratio, NRR no-response rate, PRFs Patient Record Forms, PHQ Patient Health Questionnaire, RR response rate, SRS simple random sampling, SCS Stigma Coping Scale, SCID-I Structural Clinical Interview Diagnosis I, TDM therapeutic drug monitoring

\section{Determinants of psychotropic medication non-adherence} Medication non-adherence is influenced by various factors. We systematically mapped the factors that affect medication non-adherence among patients with major psychiatric disorder into individual patient, social support, clinical or treatment and illness, and health system-related factors based on the review of 46 studies.

\section{Factors related with individual behaviors Patient's socio-demographic factors}

Some psychiatric patients' socio-demographic characteristics were associated with medication non-adherence. However, the association was inconsistent across studies. In four studies, unemployment was one of the factors associated with medication non-adherence $[25,31,56,60]$. On the other hand, the nature of the job (for example, engaging in farming activities, being busy) influenced patients' adherence to their medication [50]. Educational status was one of the influencing factors of medication non-adherence. In six studies, psychiatric patients having lower education level (lower than secondary education) were more likely to be non-adherent to their psychotropic medication compared to those patients having higher educational level $[23,40,44,52,56,57]$. Patients' nonadherence to their psychotropic medication was associated with some non-modifiable demographic factors such as age and gender) [28]. In three studies, patients aged 60 years and older were more likely to be non-adherent to their medication $[23,55,58]$. Nevertheless, one study [60] reported that young age (less than 34 years) patients were also more likely to have medication non-adherence. In three studies, the relationship of gender and medication non-adherence was inconsistent. Being female was a factor associated with medication non-adherence [52, 53, 65], but in two studies, being male also linked with medication non-adherence $[21,54]$.

\section{Patients' substance abuse}

In eight studies, both psychostimulant and psychodepressant substances misuse were associated with psychotropic medication non-adherence [23, 27, 29, 37, 42, $43,58,65]$. In three studies, psycho stimulants (e.g., cigarette smoking) was a factor associated with psychotropic medication non-adherence among major psychiatric patients $[23,25,65]$. Likewise, three studies conducted in Ethiopia [23, 25, 65] have reported that "Khat" chewing was a factor associated with psychotropic medication non-adherence among psychiatric patients. In addition, in six studies, having a history of concurrent alcohol dependency was the main factor associated with psychotropic medication non-adherence $[23,25,37,47,64,65]$.

\section{Patient attitude toward medication}

In four studies, patients' attitude toward medication was a crucial factor affecting treatment adherence and therapeutic alliance. Patients having negative attitude towards their medication was a factor associated with psychotropic medication non-adherence [23, 25, 39, 65]. Moreover, in two studies, patients having negative attitudes toward the psychotropic medication were more likely to seek alternative treatment such as traditional or religious treatment practices [21, 24]. Likewise, where patients were suspicious about the medication, believes that the medication would harm them, heard voices telling them not to take the medication, and taking medication is unnatural were less likely to adhere [36]. In three studies, psychiatric patients may also attribute to antipsychotic medication non-adherence due to the alterations in cognitive and attitudinal functioning and therefore be unwilling to use the medication $[29,37,38]$.

\section{Patients' perceived stigma}

In eight studies, the perception or the feeling of psychiatric patients being stigmatized by their families, neighbors, health professionals, and other community members was a factor associated with medication nonadherence [24, 25, 28, 36, 37, 41, 45, 65]. In one study, both internal and external triggering factors caused the patients to feel being stigmatized. Some of these included patient believe that they can get better without medicine were afraid of medication dependency and felt too embarrassed to take the medicine [24]. On the other hand, patients perceived the effects of the medication to 
Table 2 The key findings and conclusions of studies included in the systematic review and meta-analysis $(n=46)$

\begin{tabular}{lll}
\hline Author, country & Key findings (prevalence and associated factors) & Conclusion \\
\hline Ibrahim et al., & MNA was 55.7\%. Seeking for traditional treatment (OR, 6.5), male & Psycho-education on adherence and the active \\
Nigeria [21] & (OR, 3.3), low levels of insight (OR, 1.8), and low social support & involvement of the family has significant in the prevention \\
& levels (OR, 1.5) were predictors & of MNA.
\end{tabular}

Alene et al., Ethiopia [22]

The prevalence of MNA was $42.5 \%$.

Eticha et al., Ethiopia [23]

Kenfe et al., Ethiopia [24]

MNA was 26.5\%. Positive attitude (AOR, 1.4), awareness of illness $(A O R, 1.4)$, and relabel symptoms (AOR, 1.6). Khat (AOR, 0.2), illiteracy $(A O R, 0.13)$, and older age (AOR, 0.03) were the predictors of MNA.

Hibdye et al.,

Ethiopia [25]

Anne et al., USA

[26]

MNA was $41.2 \%$. Forgetfulness was attributed to $78.2 \%$ of their MNA. Irregular follow-up, poor social support, and complex drug regimen were associated with MNA.

MNA was 51.2\%. Poor social support (AOR, 5.2), stigmatized (AOR, 2.2), negative attitude $(A O R, 4.6)$, medication frequency $(A O R, 1.7)$, unemployment $(A O R, 2.1)$, and Khat chewing $(A O R, 2.1)$ were predictors.

MNA was 28\%. It was associated with perceived stigma (0.05), patient-rated severity of illness (0.05), interpersonal problems (0.02), and age 60 years or older (0.04).

Hill. et al., Ireland MNA was 24\%. It was associated with less insight, negative [27] attitudes toward medication, substance misuse, and treatment duration.

Moritz et al., Germany [28]

Mert et al., Turkey MNA for bipolar disorder, schizophrenia, and MDD was 12.1\%,

[29]

MNA was 20\%. Side-effect, missing voices, feeling of power as a motive for non-compliance, stigma, mistrust against the physician and rejection of medication were the most frequent reasons for drug discontinuation $18.2 \%$, and $24.2 \%$, respectively. Irregular follow-up $(\mathrm{OR}, 5.7)$ and diagnosis (OR, 1.5).

Novick et al., Multi-countryEuropean [30]

MA was higher in bipolar patients than in schizophrenia, which Better insight was associated with higher MA and had stronger therapeutic alliance, which reduce the clinical severity.

Hillary, Nigeria [31] Adherence varied from poor adherence (55.5\%) through moderate (36\%) to high adherence (8.5\%).

Ibrahim et al.,

Nigeria [32]

Dibonaventura et al., USA [33]

Gurmu, et al, Ethiopia [34]

MNA was $54.2 \%$ (schizophrenia $=62.5 \%$, bipolar $=45.8 \%$ ). Multiple dosing frequency $(\mathrm{OR}, 7.8)$, side-effects $(\mathrm{OR}, 6.8)$, cost of medication $(\mathrm{OR}, 4.1)$, and poly-therapy $(\mathrm{OR}, 2.3)$ were factors associated with MNA.

MA was 42.5\%. Medication side-effect and forgetfulness were $86.19 \%$ and $48.4 \%$, respectively. Agitation $(\mathrm{OR}=0.6)$, sedation/cognition $(O R=0.7)$, prolactin/endocrine $(O R=0.7)$, and side-effects $(O R=$ 0.6) were significantly associated with MNA.

MNA was 50.2\%. Schizophrenia (75.7\%), bipolar disorder (37.5\%), and depression (52.6\%). Factors were perceived recovery (26.7\%), drug unavailability (18.1\%), adverse effect (12.7\%), forgetfulness (10.6\%), and being busy (8.6\%).

Magura et al., USA Lower social support, alcohol use, lower satisfaction with [35] medication, side-effects, lower self-efficacy for avoidance and recovery, forgetfulness, unnatural to be controlled by medication, careless at times, and felt better were the reasons for MNA.

Kikkert et al., European countries [36]

Teferra et al., Ethiopia [37]

Sher et al., USA
Medication efficacy, external factors (such as patient support and therapeutic alliance), insight, side-effects, and attitudes had influence on MA.

Inadequate availability of food, perceived strength of medications, social support and safety net, lack of insight, failure to improve, side effects, substance abuse, stigma, and poor attitude of the care provider were some of the main reasons for MNA.
Caregivers' attribution of depression to cognitive and attitudinal might be schizophrenic patients had lower insight than in bipolar

MA is low and associated with pill burden, side-effect, and exposure to social drugs.

Schizophrenia patients were highly non-adherence to their medication. Intervention strategies focused on patient education can be helpful to improve adherence.

MNA among psychiatric patients in Southwest Ethiopia is high and revealed possible associated factors.

MNA was found to be high. It has significant implications to enhance level of adherence by tackling factors through intervention program.

Clinicians' should give psychological support to improve adherence

Longer treatment duration is associated with nonadherence

Approximately 1-in-5 patient had discontinued antipsychotic treatment due to forgetfulness and ambivalence toward symptoms.

MNA is a serious problem. Ensuring regular follow-up appointments and improving their thoughts are needed.

Insight and MA were found to be closely related. Insight impacts on the therapeutic alliance with mental health and associated to treatment outcomes.

More than half of the psychiatric out-patients had MNA.

Encourage rational pharmacotherapy, consider routine lower dosing prescriptions, integrating side effects surveillance, and early intervention are recommended

Medication side-effects and resource are associated with MNA. Prevention, early detection, and effective management of side-effects are crucial to avert it.

The observed rate of antipsychotic MNA in this study was high. Interventions to increase adherence are therefore crucial.

Health care providers should encourage to address patients' adherence strategies via education about sideeffects and benefits of the medication.

Professionals, care-givers, and patients do not have a shared understanding of which factors are important.

Greater attention to provision of social and financial assistance will potentially improve MNA. 
Table 2 The key findings and conclusions of studies included in the systematic review and meta-analysis $(n=46)($ Continued)

\begin{tabular}{ll}
\hline Author, country & Key findings (prevalence and associated factors) \\
\hline [38] & $\begin{array}{l}\text { problems, which significantly predicted patients' MNA. Perceived } \\
\text { stigma was also another predictor of non-adherence. }\end{array}$ \\
Mohamed et al., & $\begin{array}{l}\text { Insight and drug attitudes were associated with declining } \\
\text { schizophrenia symptoms but increasing levels of depression. } \\
\text { USA [39] }\end{array}$ \\
$\begin{array}{l}\text { Change toward more positive medication attitudes was associated } \\
\text { with changes in insight, improve community functioning, and }\end{array}$ \\
greater medication compliance.
\end{tabular}

Sava, Turkey [40] MNA was $26.5 \%$ and associated with education, lack of insight, thought they had recovered, believed that treatment had no-effect on their disorder, thinking that had recovered, not taking medication, and thought of treatment not effective.

Sirey, USA [41]

MNA was $82 \%$. Elderly (24\%) and younger (13\%) patients than older patients, stigma predicted treatment discontinuation.

Sajatovic. USA [42] MNA was 45.9\%. Younger age, unmarried, homeless, substance abuse, or fewer outpatient psychiatric visits were predictors.

Sajatovic. USA [43] MA was 51.9\%. Factors associated were younger age, comorbid substance abuse, and homelessness were the factors associated with MA level.

John, USA [44] most significantly affected patients' likelihood of MA.

Iseselo et al. Tanzania [45]

Financial constraints, lack of social support, family disruption, stigma, discrimination, and disruptive behavior were some of the influencing factors for MNA.

J.M. Olivares, Spain Minimize patients waiting stay was significantly associated with MA. [46]

Charlotte, Sweden

Adeponle, et al., Nigeria [48]

Rashid, Malaysia [49]

Roy, Ranchi (India) [50]

Omran, Iran [51] Ta [52]

Banerjee, India [53]

Oliver, Spain [54]

Dave, UK [55]

Mahaye, South Africa [56]

Sundell, Sweden [57]

Akincigil, [58] personality disorder, sensation-seeking traits, substance abuse, and unavailability of concomitant medications were predictors.

Half (50.6\%) of patients were adherent with appointments.

The type of antidepressant medication prescribed, not given a choice to choose the treating doctor, and the preference to traditional medicine were significant risk factors. illness to patients and caregivers were some of the reasons for MNA.

Non-compliance was reported as a possible cause of admission in (88.2\%) of the re-hospitalized cases. No insight to disease (59\%) and feeling of cure (27.6\%) were causes for MNA

MA was $73 \%$. Forgetting, change in routine, side effect, had lower self-efficacy, female, and had not completed post-secondary education were the most frequently identified reasons for MNA.

MNA was 66.9\%. Women (OR 2.7), consume extra pills (OR 2.8), and had a considerably lower internal locus of control (OR 4.5) were predictors

MNA was $33.9 \%$. Long-term treatment duration is a factor for MNA. Women were more adherent than men.

Discontinuation was $80 \%$. Lower discontinuation in the first 6 months after initiation was associated with higher age, weight gain, and comorbid irritable bowel syndrome.

MNA was $50.8 \%$. Age and race become predictors of MNA.

MNA was $26.1 \%$. It was less in women $(\mathrm{OR}, 0.8)$ and least 2 years of higher education (OR, 0.7), and those who received social assistance (OR, 1.3). discontinued treatment completely. Patients perceived more stigm

MNA was 77\%. Weight gain and cognitive effects of a medication

Conclusion

and attitude may improve adherence.

Better insight, positive attitudes toward medication, and educational interventions can be an important part of psychosocial rehabilitation services.

Lower education level, having thought of inadequate information about illness, and lack of insight about treatment were significantly associated with MNA.

Patients' perceptions of stigma at the start of treatment had influence their subsequent treatment behavior. Almost half of the patients had MNA that reduce the effectiveness treatments in clinical settings.

MNA is common in bipolar disorder medication.

Patients' satisfaction is seriously affect adherence. Health care providers can optimize prescribing patterns.

A collaborative approach between the care providers, leader,and family is needed.

Treatment retention had greater improvement in clinical symptoms, reduce hospital stay, and increase efficacy.

Patient and illness-related factors may imply an increased risk of MNA.

Family support was significantly associated with appointment, which can improve MA.

Involvement of patients, caregivers, flexible schedule, place choice, drug, and doctor can help to prevent MNA.

Develop community mental health care facilities and provide adequate information to patients and caregivers.

Providing a better insight about disease to patients to take their medications, even feeling of cure is important.

Clinicians should be simple and easy to address medication efficacy, tolerability, and social moderator Interventions focusing on individuals and intersectoral system-oriented approach to improve MA are needed.

Designing proper drug collection at pharmacies can improve the MA of patients.

Lack awareness was a risk for discontinuation.

Age and race were significant predictors for MNA.

MNA occurred more commonly among social support recipient

Substance abuse is one of the main risk factor for MNA 
Table 2 The key findings and conclusions of studies included in the systematic review and meta-analysis $(n=46)(C o n t i n u e d)$

\begin{tabular}{|c|c|c|}
\hline Author, country & Key findings (prevalence and associated factors) & Conclusion \\
\hline & $\begin{array}{l}\text { pharmacy utilization were associated with better adherence. } \\
\text { Younger age, substance abuse, and comorbidity were associated } \\
\text { MNA. }\end{array}$ & and needs to be targeted for intervention. \\
\hline Taj, Pakistan [1 1] & $\begin{array}{l}\text { MA among major depressive and bipolar disorders was } 61.5 \% \text { and } \\
73.9 \% \text {, respectively. Reasons were sedation }(30 \%) \text {, cost }(22 \%) \text {, } \\
\text { forgetting }(36 \%) \text {, and no explanation by doctors }(92 \%) \text {. }\end{array}$ & $\begin{array}{l}\text { MNA is a common and important issue. Treatment cost } \\
\text { and co-morbidity are common factors }\end{array}$ \\
\hline $\begin{array}{l}\text { Prukkanone et al., } \\
\text { Thailand [59] }\end{array}$ & $\begin{array}{l}\text { MA was } 41 \% \text { but all patients who attended only once were non- } \\
\text { adherent, adherence may be as low as } 23 \% \text {. }\end{array}$ & MA to antidepressant therapy for treatment was high. \\
\hline $\begin{array}{l}\text { Shigemur, Japan } \\
{[60]}\end{array}$ & $\begin{array}{l}\text { MNA was } 33.1 \% \text {. It was associated with lower age, unemployed } \\
(\mathrm{OR}, 1.9) \text {, higher daily dosing frequency, low drug satisfaction, and } \\
\text { poor doctor-patient dyad, and age (> } 34 \text { years) }(\mathrm{OR}, 1.6) \text {. }\end{array}$ & MNA was predicted by lower age and unemployment. \\
\hline $\begin{array}{l}\text { Bambouer et al., } \\
\text { USA [61]. }\end{array}$ & $\begin{array}{l}\text { MNA was } 75 \% \text {. Rates of antidepressant non-adherence significantly } \\
\text { increased over time were } 40 \% \text {. }\end{array}$ & $\begin{array}{l}\text { Effectiveness of electronically triggered, patient-specific, } \\
\text { and faxed feedback should be carefully evaluated. }\end{array}$ \\
\hline $\begin{array}{l}\text { Demyttenaere } \\
\text { et al., Belgium [62] }\end{array}$ & $\begin{array}{l}\text { MA was } 70 \% \text {, and it was decreased by } 2.5 \% \text { per month and more } \\
\text { than three times more rapidly in drop-outs. }\end{array}$ & $\begin{array}{l}\text { MA decreases with time is influenced by demographic ar } \\
\text { clinical variables. }\end{array}$ \\
\hline $\begin{array}{l}\text { Mascha C. Ten D } \\
\text { [63]. }\end{array}$ & $\begin{array}{l}\text { MNA ranged from } 39.7 \text { to } 52.7 \% \text {. It did not significantly differ } \\
\text { between intermittent ad continuation antidepressant users ( } 37.2 \% \\
\text { versus } 25 \% \text { ). }\end{array}$ & $\begin{array}{l}\text { MNA is high on MDD. Doctors continuously have to be } \\
\text { aware of this problem }\end{array}$ \\
\hline $\begin{array}{l}\text { Baldessarini et al., } \\
\text { USA [64] }\end{array}$ & $\begin{array}{l}\text { MNA was } 33.8 \% \text {. Prescribing psychiatrists considered only } 6 \% \text { as } \\
\text { MNA. Alcohol, youth, comorbidity, side effects, obsessive- } \\
\text { compulsive disorder, and recovering from mania-hypomania and } \\
\text { drug-complexity were the predictors. }\end{array}$ & $\begin{array}{l}\text { Underestimation of the problem may encourage } \\
\text { increasingly complex treatment regimens of untested } \\
\text { value, added expense, and risk of adverse effects }\end{array}$ \\
\hline $\begin{array}{l}\text { Nega et al., } \\
\text { Ethiopia [65] }\end{array}$ & $\begin{array}{l}\text { MNA was } 61.2 \% \text {. It was associated with female (AOR, 2.3), } \\
\text { combined drug (AOR, 2.7), long treatment duration (AOR, 2.3), > } 24 \\
\text { months (AOR, 2.5), substance use (AOR, 2.6), perceived stigma (AOR, } \\
\text { 2.2), patient's poor attitude (AOR, 3.0), and poor social support } \\
\text { (AOR, 1.8). }\end{array}$ & $\begin{array}{l}\text { Psychotropic MNA was high. We recommend the } \\
\text { concerned bodies to design and implement programs } \\
\text { focused on associated factors in order to improve MA. }\end{array}$ \\
\hline
\end{tabular}

AOR adjusted odds ratio, $C I$ confidence interval, MA medication adherence, MNA medication non-adherence, SCID-I Structural Clinical Interview Diagnosis I, TDM therapeutic drug monitoring

be unnatural and reported feeling better after terminating them were the factors associated with medication non-adherence [35]. Similarly, in two studies, those patients who perceived that the treatment had no effect on their illness were more likely to be non-adherent to their medication $[26,40]$. In seven studies, behavioral factors such as forgetting the right dose and right time of taking medication were the factors associated with medication non-adherence [11, 22, 24, 28, 34, 35, 52]. In six studies, patients and caregivers reported being busy with daily routines, careless about the timing, forgetting to remember medication time, and irregular follow-up were associated with medication non-adherence $[11,22,24,34$, $35,52]$. In the worst scenario, patients' complete rejection of the medication was a main cause of discontinuation and non-adherence to their medication [28].

\section{Clinical factors}

The clinical factors of medication non-adherence were re-categorized into medication side-effect, lack of insight about their illness and treatment, comorbidity, medication efficacy, long treatment duration, and complexity of the prescribed medication.

\section{Medication side-effects}

In several studies, psychotropic medication nonadherence was associated with medication-related sideeffects [11, 22-25, 28-30, 32-37, 39, 44, 50, 52, 55, 64, 65]. In seven studies, patients feeling dizziness, fatigue, tiredness, sedation, lethargy, and sleepiness were the most frequently reported side-effects that contributed to medication non-adherence [11, 33, 36, 37, 50, 52, 65]. In two studies, sleepiness during day time (medication dose time) and potentially life-threatening or distressing side-effects seriously affected patients' medication non-adherence [37, 44]. Another two studies, feeling of powerlessness, insomnia, difficulty thinking or concentrating, restlessness, or feeling jittery were found to be associated with medication non-adherence [28, 37]. Likewise, in five studies, weight gain was another medication-related side-effect that associated with medication non-adherence and patients' perception toward their medication $[25,33,36,44,55]$.

In two studies, side-effects such as decreased sexual interest and having a symptom of sexual dysfunction were associated with patients' medication adherence [33, 36]. Moreover, patients and caregivers' perceived medication adverse drug reaction was a factor associated with psychotropic medication non-adherence [34, 36]. 


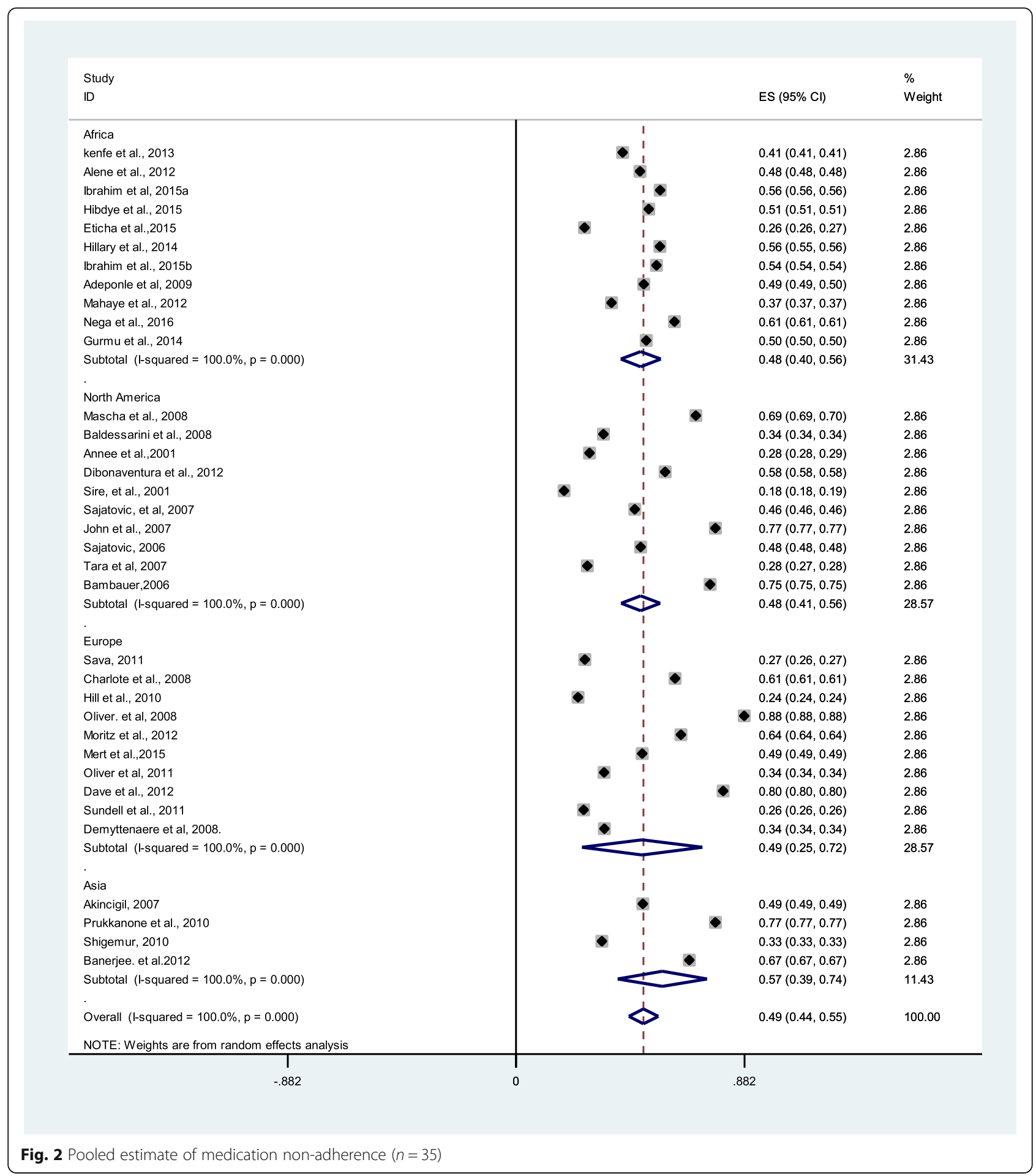

Likewise, extra pyramidal symptoms or agitation [33], other medication-related side-effects such as cognitive deterioration or impairment [44], missing voice [28], paralysis of body parts, twisting of the neck, drooling, weakness, appetite stimulation [37], severe depressive symptoms and episodes [39, 44], salivation, dry mouth, and memory problem [50] were common factors associated with medication non-adherence.

\section{Lack of insight about illness and medication}

In seven studies, patients' lack of insight (level of awareness or understanding) about their illness and medication was a 


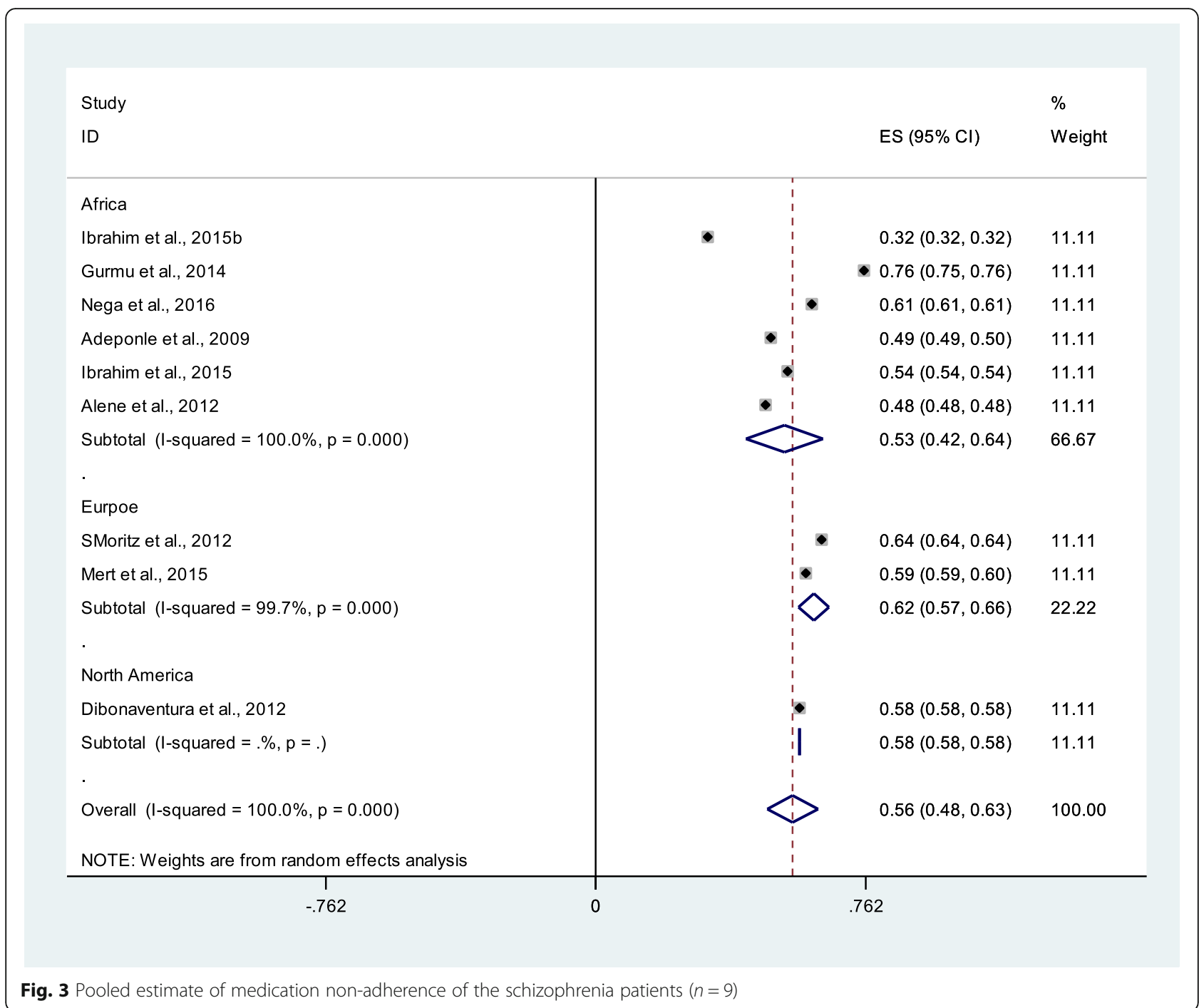

common factor associated with psychotropic medication non-adherence [21, 23, 28, 39, 40, 50, 51]. Likewise, misunderstanding about the treatment consequences, lack of awareness of their illness and or mental disorder in general, and sometimes appreciating subjective relief symptoms [30, $36,37]$ were the factors associated with medication nonadherence among major psychiatric disorder patients.

\section{Medication efficacy}

The pharmacological management of psychiatric disorders needs safe and efficacious medication to achieve desired treatment goals. The fact that lower medication efficacy and patient self-rating of efficacy were also factors associated with psychotropic medication non-adherence. Taking lower potent concomitant psychotropic medications [47, 65], recovery from illness [34], felt better [24, 52], and failure to improve with medication [37] were the factors associated with medication efficacy related with psychotropic medication non-adherence. Likewise, patients' or caregivers' perceived medication efficacy such as subjective relief of symptoms, patients' feel drugs have no effect on the illness, not helpful, being ineffective [36, 46, 50], and feeling of cured [51] were side-effect-related factors associated with medication non-adherence.

\section{Medication duration}

In five studies, long treatment duration (6-12 months and longer) was an associated factor for medication nonadherence [22, 25, 37, 43, 65]. Similarly, having long-term medication prescriptions, long duration maintenance therapy [29, 54], and irregular follow-up [29] were associated with psychotropic medication non-adherence.

\section{Treatment complexity}

In three studies, multiple dose, frequency and drug combinations, or complex drug regimen were seriously linked with medication non-adherence [24, 32, 64]. In two studies, pill burden or consuming extra pills was 


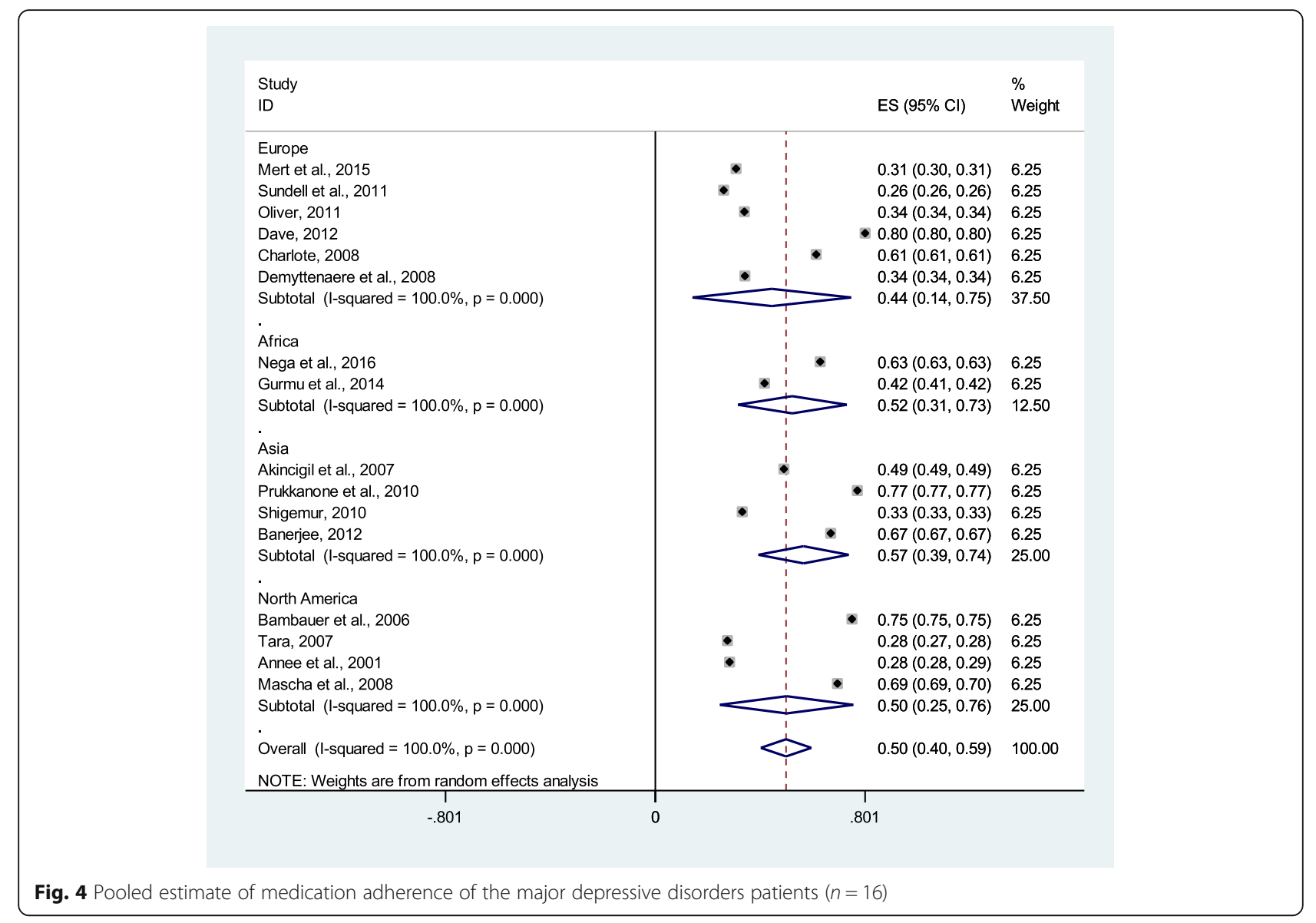

also one of treatment-related factors that negatively influenced patients' adherence to their psychotropic medication [22, 53]. In another two studies, taking medication twice per day was a negative factor for medication adherence $[46,49]$. In addition, the route of medication administration had a significant effect on medication non-adherence. The patients on injectable medication were more likely to be adherent than the patient taking drugs orally [46].

\section{Co-morbidity}

In three studies, psychotropic medication adherence was compromised where there were co-morbidities of mental illness and other physical illnesses. Studies [11, 43, 64] reported that medication non-adherence was associated with patients having co-morbidities with their current psychiatric disorders. Of these, affective morbidity, obsessive-compulsive disorders, recovering from maniahypomania [64], personality disorders and sensation of seeking personality traits [47], and alcohol abuse disorders [61] were negatively associated with medication adherence. Irritable bowel syndrome as a co-morbidity was also significantly associated with medication nonadherence [55].

\section{Lack of social support}

In seven studies, poor or lack of social or family support was associated with psychotropic medication nonadherence [21, 24, 25, 35, 37, 45, 65]. In two studies, limited or inadequate patient information, weak professional or family support, therapeutic alliance, social involvement, and low education were some of the social support-related factors [36, 37]. Cohesiveness, family reminding, and transport to hospital [37], lower family harmony or lack of resilient family support, discrimination by nearby people, disruption of family functioning or household routine and religious practices [45], weak community functioning [39], homelessness [42, 43], had old age caregivers or lack of caregivers [50], lack of family compliance of follow-up [51], lack of advice about their medication intake from friends and relatives [28], not receiving social assistance [57], and caregivers' attribution of depression to cognitive and attitudinal problem [38] were the factors associated with psychotropic medication non-adherence.

\section{Health system-related factors}

The health system-related factor was the crucial area for getting quality mental health service. In three studies, 


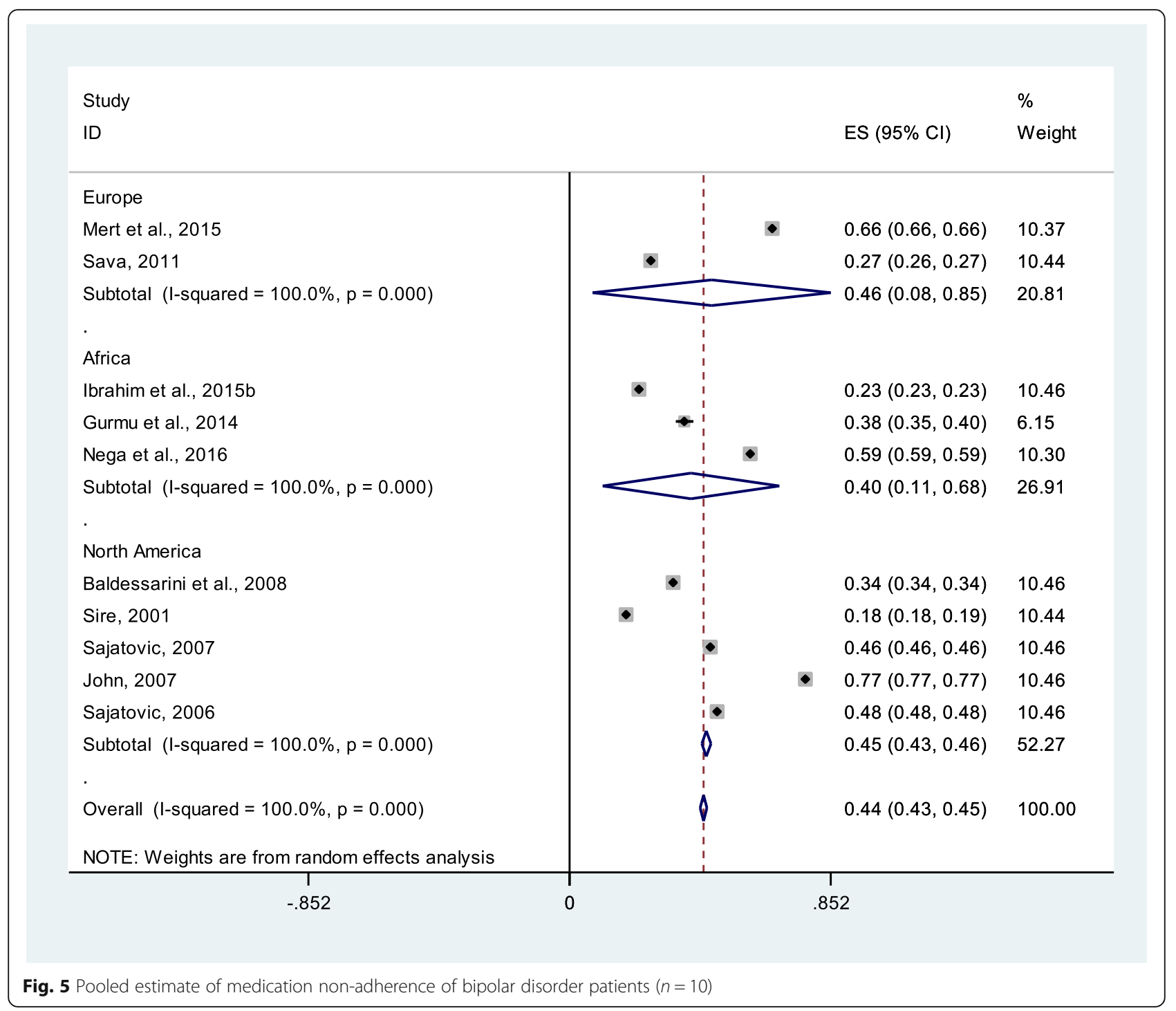

medication non-adherence was associated with lack of free access to medicine due to inadequate or unavailability of psychotropic drug supplies in health facilities [24, $25,34]$. In one study, although psychotropic medications were normally provided free of charge in the government health facilities, patients were suffering unavailable of medication in the government pharmacies. Thus, patients need to buy from private pharmacies which are very expensive and lead to interruption of the medication. In addition, health care provider sometimes changes the drug but it may not be found in the government hospital pharmacy [45]. Therefore, the lack of alternative drug or therapy affects psychotropic medication adherence [39]. On the other hand, the lack of sufficient and quality health education to psychiatric patients and or their caregivers/relatives/families about the medication and illness influenced patients' adherence to their prescribed medication $[22,36,39,40,51]$.
In three studies, patient-physician or therapist relationship was crucial for better medication adherence. Consequently, unfriendly, judgmental behavior, inflexible appointment systems, mistrust, and having negative patient-physician relationships were the factors associated with patients' psychotropic mediation non-adherence [28, 30, 60]. In one study, health care providers' negative attitude had influenced patients' adherence to the medication and their follow-ups [37]. Similarly, in two studies, health professional shortages had also affected medication adherence [49, 58]. Patient preference for traditional/complementary medicine was another cause of medication non-adherence [49]. Medication non-adherence was affected by the number of hospitalizations [28], irregular hospitalization and frequently discharge of patients, length of stay [42, 46], lack of patients' satisfaction with health care services [44], and long distance to access the health service/recollect medications [50]. In three studies, health care providers would be unable to explain 
and optimize prescribing pattern, timing, and dose benefit of medication. In addition, the lack of friendly deal with medication complexity, tolerability, efficacy, and health belief issues were critical factors influence medication adherence $[11,44,52]$. Furthermore, the health care system has also associated with medication non-adherence. These factors were poor service structure and cumbersome purchasing procedure (affect access), availability and timely use or collection of psychotropic medication during follow-up visit, and patients not covered by health insurance scheme [58].

\section{Medication cost}

In seven studies, psychiatric patients and their caregivers having financial constraints to buy medicines were factors associated with medication non-adherence. In addition, the lack of money for transportation, to purchase proper food, and to buy medications were the factors associated with patients' adherence to their medication. Psychotropic medications had an appetite stimulation that has been increasing food demand which incurs an additional economic burden [11, 24, 32, 37, 42, $45,50]$ and contribute for medication non-adherence.

\section{Discussion}

This systematic review and meta-analysis determined the pooled proportion of psychotropic medication nonadherence and synthesized the associated factors with medication non-adherence among major psychiatric disorder patients. Almost half (49\%) of patients with major psychiatric disorders did not adhere to their psychotropic medication. Medication non-adherence among patients with schizophrenia, major depressive disorder, and bipolar disorder were $56 \%, 50 \%$, and $44 \%$, respectively. Medication non-adherence is influenced by various factors such as patients' individual behavior, social or family support, clinical or illness and treatment-related, and overall health care system-related factors.

Previous systematic reviews have indicated that medication non-adherence is a common challenge in the treatment of psychiatric disorders [72, 73]. This meta-analysis finding is consistent with a systematic review revealed an overall medication adherence level of 58\% (ranged from 24 to $90 \%$ ), and medication adherence to antidepressants was $65 \%$ [6]. Another earlier systematic review has shown that the level of medication non-adherence was $60 \%$ [74]. The present systematic review and meta-analysis finding is consistent with a finding from a comprehensive systematic review on schizophrenia which reported that a mean rate of non-adherence was $41.2 \%$. The sub-group analysis indicated that a mean non-adherence rate was 49.5\% [14], and another systematic review has shown that psychotropic mediation non-adherence was 44\% [75]. Nevertheless, the present meta-analysis finding is a bit lower than a finding from a systematic review which revealed that adherence in psychiatric patients ranged from 10.7 to $38 \%$ [76].

This systematic review of factors influencing psychotropic medication non-adherence which is consistent with other systematic reviews [14, 72, 73, 77] has shown that medication adherence is mainly affected by patients' negative attitude toward their medication, lack of insight, negative health belief, and perceived stigma. Similarly, medication non-adherence is consistently associated with patients behavioral practices (e.g., substance abuse) $[14,74]$ and also patients' socio-demographic characteristics (such as educational status, age, gender, and employment) [14, 72]. The present systematic review has identified that the lack of social support is associated with medication non-adherence among major psychiatric disorder patients. This is similar with other reviews, which have reported that the lack of family involvement, care/dyad support, and other social supports are strongly negatively associated with poorer therapeutic alliance $[14,72,75,76]$. In addition, medication non-adherence is associated with clinical- or medication-related factors [14, 72-74, 77]. This finding is supported by another systematic review which revealed that psychiatric disorder comorbidities with other physical disorders influence medication adherence and increase re-admission of psychiatric patients $[73,78,79]$.

In the present systematic review, medication nonadherence is associated with poor functioning of the health system such as lack of psychotherapy, lack of information, long treatment duration with little health personnel follow-up, inadequate discharge planning, increased hospitalizations, poor support and care environment, experiencing access barriers to high-quality care and health care providers unable to provide elicit information on adherence, inadequate medication coverage, and poorer therapeutic alliance [14, 72, 74-76, 79]. Financial factors seriously affected medication adherence. These included unaffordability of medication, increased health care cost $[73,74]$, lack of health insurance [75], patients' poor capacity, and limited resources [73].

A large amount of heterogeneity in the definition and measurement methods used to assess medication adherence have been reported in some reviews. The heterogeneity of factors related to non-adherence calls for individually tailored approaches to promote adherence $[80,81]$. Non-adherence contributes enormously to poor health outcome and needs substantial work to improve treatment outcomes [80]. Evidence showed that improving adherence to psychotropic medications could have a positive impact on patients and society. Non-adherence issues need to be looked at from many angles and taking a multifaceted approaches with patients and healthcare providers to address identified challenges [81]. 


\section{Conclusions}

Almost half of patients with major psychiatric disorder did not adhere to their psychotropic medication. Patients' individual behavior, lack or poor social/family support, treatment and illness-related clinical conditions, and the health system barriers are influencing factors of psychotropic medication non-adherence among patients with major psychiatric disorders. Therefore, multifaceted intervention is needed to create supportive environment for patients and caregivers to minimize psychotropic medication nonadherence. Additionally, supportive social and health care system programs should be designed to alleviate major psychiatric disorder patients' medication non-adherence. Comprehensive approaches targeting the factors that affect medication non-adherence can bring tremendous positive outcomes. This systematic review and meta-analysis finding can be helpful to inform policy-makers, clinicians, and other caregivers to undertake necessary decisions to establish an integrated approach to boost therapeutic alliance and improve medication adherence.

\section{Supplementary information}

Supplementary information accompanies this paper at https://doi.org/10. 1186/s13643-020-1274-3

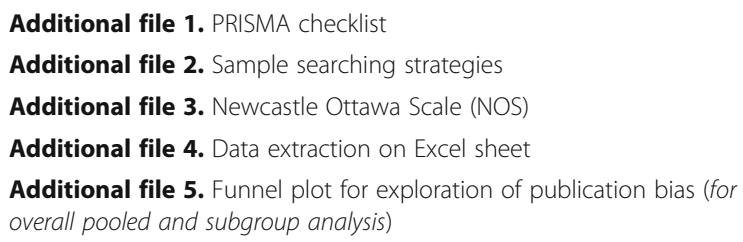

\section{Abbreviations}

AOR: Adjusted odds ratio; Cl: Confidence interval; MA: Medication adherence; MNA: Medication non-adherence; NRR: No response rate; PRISMA: Preferred Reporting Items for Systematic Review and Meta-Analysis; PROSPERO: Prospective Register of Systematic Reviews; RR: Response rate; TDR: Tropical Disease Research; US: United States; WHO: World Health Organization

\section{Acknowledgements}

We thank TDR/WHO international postgraduate scholarship program and School of Public Health, University of Ghana, for financial support. We thank College of Health and Medical Sciences, Haramaya University, for office arrangement.

\section{Authors' contributions}

$A S, K T, A M$, and AA conceived and designed the study. AS drafted the manuscript and is the guarantor of the systematic review and meta-analysis. AS and GT developed the search strings and performed searching the studies, selection of the studies, data extraction, and synthesis. AS, KT, AM, NA, GT, and AA extensively reviewed the manuscript and incorporated intellectual inputs. All authors read, provided feedback, and approved the final version of the manuscript.

\section{Funding}

This work has been funded by TDR, the Special Programme for Research and Training in Tropical Diseases, which is hosted at the World Health Organization and co-sponsored by UNICEF, UNDP, the World Bank, and WHO. The grant number for the University of Ghana is B40300.

\section{Availability of data and materials}

The data that support the review findings are available upon submitting a reasonable request to the corresponding author.

Ethics approval and consent to participate

Not applicable.

\section{Consent for publication}

Not applicable.

\section{Competing interests}

The authors declare that they have no competing interests.

\section{Author details}

${ }^{1}$ Department of Population, Family and Reproductive Health, School of Public Health, College of Health Sciences, University of Ghana, Accra, Ghana. ${ }^{2}$ College of Health and Medical Sciences, Haramaya University, Po Box 235, Harar, Ethiopia. ${ }^{3}$ Population Council/Ghana, Yiyiwa Drive, Accra, Ghana.

Received: 9 April 2018 Accepted: 6 January 2020

Published online: 16 January 2020

\section{References}

1. WHO. The bare facts, Geneva. Geneva: WHO; 2008

2. WHO. Mental disorders fact sheet. Reviewed April. Geneva; 2016. Available from: http://www.who.int/mediacentre/factsheets/fs396/en/. Accessed 16 Mar 2017

3. World Bank Group and, WHO. Out of the shadows: making mental health a global development priority organized by World Bank Group\&WHO, April 1314. Washington D.C; 2016. Available from: http://www.worldbank.org/en/ events/2016/03/09/out-of-the-shadows-making-mental-health-a-global-priority

4. WHO. Comprehensive Mental Health Action Plan 2013-2020. Geneva: World Helath Organziation; 2013. https://www.who.int/mental_health/action_ plan_2013/en/.

5. Mathers CD, Loncar D. Projections of global mortality and burden of disease from 2002-2030. PLoS Med. 2006;3:e442.

6. Cramer JA, Rosenheck R. Compliance with medication regimens for mental and physical disorders. Psychiatr Serv. 1998;49(2):196-201.

7. Farooq S, Naeem F. Tackling nonadherence in psychiatric disorders: current opinion. Review. Dovepress Neuropsychiatr Dis Treat. 2014;10:1069-77.

8. Colom F, Vieta E. Non-adherence in psychiatric disorders: misbehaviour or clinical feature? Acta Psychiatr Scand. 2002;105:161-3.

9. WHO. Adherence to long-term therapies; Evidence for action. Geneva: World Health Organization; 2003. https://apps.who.int/iris/bitstream/ handle/10665/42682/9241545992.pdf;jsessionid.

10. Rekha R, Masroor J, Sushma K, et al. Reasons for drug non-compliance of psychiatric patients. J Indian Acad Appl Psychol. 2005;31(1):24-8.

11. Taj F, Tanwir M, Aly Z, Khowajah AA, Tariq A, Syed FK, et al. Factors associated with non-adherence among psychiatric patients at a Tertiary Care Hospital, Karachi, Pakistan: a questionnaire based cross-sectional study. J Pak Med Assoc. 2008;58(432):432-6.

12. Smith F, Clifford S. Adherence to medication among chronic patients in Middle Eastern countries: review of studies. East Mediterr Heal J. 2011;17(4):356-63.

13. Lindstrom E, Bingefors K. Patient compliance with drug therapy in schizophrenia: economic and clinical issues. Pharmacoeconomics. 2000; 18(2):106-24.

14. Dunn LB, Leckband S, Dolder CR, Pharm D, Leckband SG, Ph R, et al. Prevalence of and risk factors for medication nonadherence in patients with schizophrenia. J Clin Psychiatry. 2002;63(10):892-909.

15. Burton WN, Chen C-Y, Conti DJ, Schultz AB, Edington DW. The association of antidepressant medication adherence with employee disability absences. Am J Manag Care. 2007;13(2):105-13.

16. Semahegn A, Torpey K, Manu A, Assefa A, Tesfaye G, Ankomah A. Psychotropic medication non-adherence and associated factors among adult patients with major psychiatric disorders: a protocol for systematic review and meta-analysis. PROSPERO. 2017. CRD42017067436. https://www. crd.york.ac.uk/prospero/display_record.php?ID=CRD42017067436.

17. Moher D, Shamseer L, Clarke M, Ghersi D, Liberati A, Petticrew M, et al. Preferred reporting items for systematic review and meta-analysis protocols (PRISMA-P) 2015 statement. Syst Rev. 2015:4(1):1-9 Available from: http:// www.systematicreviewsjournal.com/content/4/1/1. 
18. Semahegn A, Torpey K, Manu A, Assefa N, Tesfaye G, Ankomah A. Psychotropic medication non-adherence and associated factors among adult patients with major psychiatric disorders: a protocol for a systematic review. BMC Syst Rev. 2018;7:10.

19. Rutgers. RUTGERS the state University of New Jersey. In: George F, editor. Smith Library of the Health Sciences. EndNoteX8.0.1(Bld 10444), Cite While You Write TM Patented technology U.S patent number 8,092,241: University of Ghana; 2017. 3091850168. Available from: http://www.libraries.rutgers. edu/sites/default/files/smith/pdf/EndNoteBasic.pdf.

20. Wells G, Shea B, O'Connell D, Peterson J, Welch V, Losos M, et al. The Newcastle-Ottawa Scale (NOS) for assessing the quality of nonrandomised studies in meta-analyses. Ottawa: Ottawa Health Research Institute; 2010.

21. Ibrahim AW, Yahya S, Pindar SK, Wakil MA, Garkuwa A, Sale S. Prevalence and predictors of sub-optimal medication adherence among patients with severe mental illnesses in a tertiary psychiatric facility in Maiduguri, Northeastern Nigeria. Pan Afr Med J. 2015;21:39.

22. Alene M, Wiese MD, Angamo MT, Bajorek BV, Yesuf EA, Wabe NT. Duplicateadherence to medication for the treatment of psychosis: rates and risk factors in an Ethiopian population. BMC Clin Pharmacol. 2012;12:10.

23. Eticha T, Teklu A, Ali D, Solomon G, Alemayehu A. Factors associated with medication adherence among patients with schizophrenia in Mekelle, Northern Ethiopia. PLoS One. 2015;10(3):e0120560. Laks J, editor; [cited 2017 Jun 18]. https://doi.org/10.1371/journal.pone.0120560.

24. Tesfay K, Girma E, Negash A, Tesfaye M. Non-adherence among adult psychiatric out patients in Jimma University Specialized Hospital, Southwest Ethiopia. Ethiop J Health Sci. 2013;23(3):227-38.

25. Hibdye G, Dessalegne Y, Debero N, Bekan L, Sintayehu M. Prevalence of drug non-adherence and associated factors among patients with bipolar disorder at outpatient unit of Amanuel Hospital, Addis Ababa, Ethiopia. J Psychiatry. 2015;1:003. https://doi.org/10.4172/2378-5756.S1-003.

26. Sirey JA, Bruce ML, Alexopoulos GS, Perlick DA, Friedman SJ, Meyers BS. Perceived stigma and patient-rated severity of illness as predictors of antidepressant drug adherence. Psychiatr Serv. 2001;52(12):1615-20.

27. Hill M, Crumlish N, Whitty P, Clarke M, Browne S, Kamali M, et al. Nonadherence to medication four years after a first episode of psychosis and associated risk factors. Psychiatr Serv. 2010;61(2):189-92. [cited 2017 Jun 18]. https://doi.org/10.1176/ps.2010.61.2.189.

28. Moritz S, Favrod J, Andreou C, Morrison AP, Bohn F, Veckenstedt R, et al. Beyond the usual suspects : positive attitudes towards positive symptoms is associated with medication noncompliance in psychosis. Schizophr Bull. 2013:39(4):917-22.

29. Mert DG, Turgut NH, Kelleci M, Murat S. Perspectives on reasons of medication nonadherence in psychiatric patients. Patient Prefer Adherence. 2015;9:87-93.

30. Novick D, Montgomery W, Treuer T, Aguado J, Kraemer S, Haro JM. Relationship of insight with medication adherence and the impact on outcomes in patients with schizophrenia and bipolar disorder: results from a 1-year European outpatient observational study. BMC Psychiatry. 2015; 15(1):189. [cited 2017 Jun 18]. https://doi.org/10.1186/s12888-015-0560-4.

31. Odo HO, Agbonile IO, Esan PO, Jeffrey S, BOJ S. Assessment of adherence to psychotropic medications among out-patients at the Pharmacy Department of a Psychiatric Hospital, in Benin City, Nigeria. Asian J Pharm. 2014;8:211-5.

32. Ibrahim A, Pindar SK, Yerima MM, Rabbebe IB, Shehu S, Garkuwa HA, et al. Medication-related factors of non adherence among patients with schizophrenia and bipolar disorder: outcome of a cross-sectional survey in Maiduguri, North-eastern Nigeria. J Neurosci Behav Heal. 2015;7(5):31-9.

33. Dibonaventura M, Gabriel S, Dupclay L, Gupta S, Kim E. A patient perspective of the impact of medication side effects on adherence: results of a cross-sectional nationwide survey of patients with schizophrenia. BMC Psychiatry. 2012;12:20.

34. Gurmu AE, Abdela E, Allele B, Cheru E, Amogne B. Rate of non-adherence to antipsychotic medications and factors leading to non-adherence among psychiatric patients in Gondar University Hospital, Northwest Ethiopia. Hindawi Publ Corp. Advances in Psychiatry.2014;2014:ID 475812. https:// www.hindawi.com/journals/apsy/2014/475812/.

35. Magura S, Rosenblum A, Fong C. Factors associated with medication adherence among psychiatric outpatients at substance abuse risk. $\mathrm{NIH}$ Public Access Open Addict J. 2012;4:58-64.

36. Kikkert MJ, Schene AH, Maarten WJ, Robson D, Born A, Helm H, et al. Medication adherence in schizophrenia: exploring patients', carers' and professionals' views. Schizophr Bull. 2006;32(4):786-94.
37. Teferra S, Hanlon C, Beyero T, Jacobsson L, Shibre T. Duplicated-perspectives on reasons for non-adherence to medication in persons with schizophrenia in Ethiopia: a qualitative study of patients, caregivers and health workers. BMC Psychiatry. 2013;13:168.

38. Sher I, McGinn L, Sirey JA, Meyers B. Effects of caregivers' perceived stigma and causal beliefs on patients' adherence to antidepressant treatment. Psychiatr Serv. 2005;56(5):564-9.

39. Mohamed S, Rosenheck R, Mcevoy J, Swartz M, Stroup S, Lieberman JA. Cross-sectional and longitudinal relationships between insight and attitudes toward medication and clinical outcomes in chronic schizophrenia. Schizophr Bull. 2009:35(2):336-46.

40. Savaş HA, Unal A, Vırıt O. Original papers/Araştırmalar treatment adherence in bipolar disorder. J Mood Disord. 2011;1(3):95-102.

41. Sirey JA, Bruce ML, Alexopoulos GS, Perlick DA, Raue P, Friedman SJ, et al. Discontinuation in young and older outpatients perceived stigma as a predictor of treatment with depression. Am J Psychiatry. 2001;158(3):479-81.

42. Sajatovic M, Valenstein M, Blow F, Ganoczy D, Ignacio R. Treatment adherence with lithium and anticonvulsant medication among patients with bipolar disorder. Psychiatr Serv. 2007:58(6):855-63.

43. Sajatovic M, Valenstein M, Fc B, Ganoczy D, Rv I. Treatment adherence with antipsychotic medications in bipolar disorder. Bipolar Disord. 2006:8:232-41.

44. Johnson FR, Özdemir S, Manjunath R, Hauber AB, Burch P, Thompson TR, et al. Approach linked references are available on JSTOR for this article: factor treatments a stated-preference approach. Med Care. 2007;45(6):545-52.

45. Iseselo MK, Kajula L, Yahya-malima KI. The psychosocial problems of families caring for relatives with mental illnesses and their coping strategies: a qualitative urban based study in Dar Es Salaam. BMC Psychiatry. 2016;16:1-12.

46. Olivares JM, Rodriguez-morales A, Diels J, Povey M. Long-term outcomes in patients with schizophrenia treated with risperidone long-acting injection or oral antipsychotics in Spain: results from the electronic schizophrenia treatment adherence registry (e-STAR ) *. Eur Psychiatry. 2009;24(5):287-96.

47. Åkerblad A, Bengtsson F, Holgersson M, Von Knorring L. Identi fi cation of primary care patients at risk of nonadherence to antidepressant treatment. Patient Prefer Adherence. 2008:2:379-86.

48. Adeponle AB, Thombs BD, Adelekan ML, Kirmayer LJ. And medication adherence at a Nigerian psychiatric hospital family participation in treatment, post-discharge appointment and medication adherence at a Nigerian psychiatric hospital. Br J Psychiatry. 2009;194:86-7.

49. Rashid AK, Rahmah MA. Treatment related risk factors associated with the default of depression treatment among the elderly: a case-control study. Open Geriatr Med J. 2010;3:11-6.

50. Roy R, Jahan M, Kumari S. Reasons for drug non-compliance of psychiatric patients: a centre-based study. J Indian Acad Appl Psychol. 2005;31(1):24-8.

51. Omranifard V, Yazdani M, Yaghoubi M, Namdari M. Noncompliance and its causes resulting in psychiatric readmissions. Iran J Psychiatry. 2008;3(1):37-42.

52. Burra TA, Chen E, Mcintyre RS, Grace SL, Blackmore ER, Stewart DE, et al. Predictors of self-reported antidepressant adherence predictors of selfreported antidepressant. Behav Med. 2007;32(4):127-34.

53. Banerjee S. Factors affecting non-adherence/compliance among patients diagnosed with unipolar depression in a psychiatric department of a general hospital in Kolkata, India. Trivandrum: Achutha Menon Centre for Health Science Studies, Sree Chitra Tirunal Institute fo; 2012.

54. Lacasta-tintorer D, García-lecina R, Flamarich-zampalo D, Font-canal T, Martín MIF. Do depressed patients comply with treatments prescribed? A cross-sectional study of adherence to the antidepressant treatment. Actas Esp Psiquiatr. 2011;39(5):288-93.

55. Davé S, Classi P, Le TK, Maguire A, Ball S. Discontinuation of antidepressant therapy among patients with major depressive disorder. Open J Psychiatry. 2012:2:272-80.

56. Mahaye S, Mayime T, Nkosi S, Mahomed FN, Pramlal J, Setlhabana O, et al. Medication adherence of psychiatric patients in an outpatient setting. African J Pharm Pharmacol. 2012;6(9):608-12.

57. Sundell KA, Waern M, Petzold M, Gissler M. Socio-economic determinants of early discontinuation of anti-depressant treatment in young adults. Eur J Pub Health. 2011;23:1-7.

58. Akincigil A, Bowblis JR, Levin C, Walkup JT, Saira Jan P, Crystal S. Adherence to antidepressant treatment among privately insured patients diagnosed with depression. NIH Public Access Med Care. 2007:45(4):363-9.

59. Prukkanone B, Vos T, Burgess P, Chaiyakunapruk N, Bertram M. Adherence to antidepressant therapy for major depressive patients in a psychiatric hospital in Thailand. BMC Psychiatry. 2010;10:64. 
60. Shigemura J, Ogawa T, Yoshino A, Sato Y, Nomura S. Predictors of antidepressant adherence: results of a Japanese internet-based survey. Psychiatry Clin Neurosci. 2010;64:179-86.

61. Bambauer KZ, Adams AS, Zhang F, Minkoff N, Grande A, Weisblatt R, et al. Physician alerts to increase antidepressant adherence. Arch Intern Med. 2006;166:498-504

62. Demyttenaere K, Adelin A, Patrick M. Six-month compliance with antidepressant medication in the treatment of major depressive disorder. Int Clin Psychopharmacol. 2008;23:36-42.

63. Mascha C, Bockting CLH, Schene AH. Adherence to continuation and maintenance antidepressant use in recurrent depression. J Affect Disord. 2009;115:167-70.

64. Baldessarini RJ, Perry R, Pike J. Factors associated with treatment nonadherence among US bipolar disorder patients. Hum Psychopharmacol Clin Exp. 2008:23:95-105.

65. Nega M, Semahegn A, Demissie M. Psychotropic medication non-adherence and associated factors among patients with severe psychiatric disorders attending psychiatry clinics in selected hospitals, eastern Ethiopia: a crosssectional study. Unpubl Thesis 2016

66. Barendregt JJ, Doi SA, Lee YY, Norman RE, Vos T. Meta-analysis of prevalence. J Epidemiol Community Health. 2013;67:974-8.

67. Stroup DF, Berlin JA, Morton SC, Olkin I, Williamson GD, Rennie D, et al. Meta-analysis of observational studies in epidemiology. A proposal for reporting. JAMA. 2000;283(15):2008-12.

68. Higgins JPT, Thompson SG. Quantifying heterogeneity in a meta-analysis. Stat Med. 2002:1558:1539-58

69. Higgins JPT, Altman DG, Gøtzsche PC, Jüni P, Moher D, Oxman AD. The Cochrane collaboration's tool for assessing risk of bias in randomised trials. BMJ. 2011;343:d5928.

70. DerSimonian R, Laird N. Meta-analysis in clinical trials revisited: HHS Public Access. Contemp Clin Trials. 2015;45(0 0):139-45.

71. Egger M, Smith GD, Schneider M, Minder C. Bias in meta-analysis detected by a simple, graphical test. BMJ. 1997;315:629-34.

72. Colom F, Vieta E, Tacchic M, Sanchez-Moreno J, Scott J. Identifying and improving non-adherence in bipolar disorder Identifying and improving non-adherence in bipolar disorders. Bipolar Disord. 2005;7(Suppl 5):24-31.

73. Chapman SCE, Horne R. Medication nonadherence and psychiatry: review. Curr Opin Psychiatry. 2013;26(5):446-52.

74. Kreyenbuhl J, Record EJ, Palmer-bacon J. A review of behavioral tailoring strategies for improving medication adherence in serious mental illness. Clin Res. 2016;18(2):191-201.

75. Lanouette NM, Folsom DP, Sciolla A, Jeste DV. Psychotropic medication nonadherence among United States Latinos : a comprehensive literature review. Psychiatr Serv. 2009;60(2):157-74.

76. Smith D, Lovell J, Weller C, Kennedy B, Winbolt M, Young C, et al. A systematic review of medication non-adherence in persons with dementia or cognitive impairment. PLoS One. 2017;12(2):e0170651.

77. Aikens JE, Nease DE, Nau DP, Klinkman MS, Schwenk TL. Adherence to maintenance-phase antidepressant medication as a function. Ann Fam Med. 2005:3(1):23-30

78. Lilijana Š, Zvezdana M, Wahlbeck K, Haaramo P. Psychiatric readmissions and their association with physical comorbidity: a systematic literature review. BMC Psychiatry. 2017;17(2):1-17.

79. Masand PS, Roca M, Martin S, Turner JMK. Partial adherence to antipsychotic medication impacts the course of illness in patients with schizophrenia: a review. Prim Care Companion J Clin Psychiatry. 2009;1 1(4):148-55.

80. Barkhof E, Meijer CJ, De Sonneville LMJ, Linszen DH, De Haan L. Interventions to improve adherence to antipsychotic medication in patients with schizophrenia - a review of the past decade. Eur Psychiatry. 2012;27:9-18.

81. Higashi K, Medic G, Littlewood KJ, Diez T, Granström O, De Hert M. Medication adherence in schizophrenia: factors influencing adherence and consequences of nonadherence, a systematic literature review. Ther Adv Psychopharmacol Orig. 2013;3(4):200-18.

\section{Publisher's Note}

Springer Nature remains neutral with regard to jurisdictional claims in published maps and institutional affiliations.

Ready to submit your research? Choose BMC and benefit from:

- fast, convenient online submission

- thorough peer review by experienced researchers in your field

- rapid publication on acceptance

- support for research data, including large and complex data types

- gold Open Access which fosters wider collaboration and increased citations

- maximum visibility for your research: over $100 \mathrm{M}$ website views per year

At BMC, research is always in progress.

Learn more biomedcentral.com/submissions 